\title{
The Natural Killer Cell: A Historical Perspective and the Use of Supplements to Enhance NKC Activity
}

\author{
Jerry T. Thornthwaite ${ }^{1,2}$, Hare $\mathrm{Shah}^{2}$, Pashupati Shah ${ }^{2}$, Henry Respess ${ }^{2}$ \\ ${ }^{1}$ Department of Chemistry \& Engineering Sciences, Freed Hardeman University, Henderson, USA \\ ${ }^{2}$ The Cancer Research Institute of West Tennessee, Henderson, USA \\ Email: jtt@criwt.com
}

Received August 14, 2012; revised September 20, 2012; accepted October 3, 2012

\begin{abstract}
The Natural Killer Cell (NKC) is the cell-mediated cornerstone of innate immunity. The purpose of this reviewis to give a historical perspective of the discovery of the Natural Killer Cell (NKC) and to apply the use of supplements in the enhancement of NKC in human cancers for the developmentof human health and well-being. Since the discovery of the NKC, as observed by Nomarski optics, scanning (SEM)/transmission electron microscopy (TEM) with cellular numeration and enrichment using bovine serum albumin (BSA) continuous gradients, there have been significant research and clinical studies to increase the effectiveness of NKC in the destruction of cancer cells. Based on significant research and clinical studies, at least 16 components have been identified that enhance or may enhance, based on their immune modulator activity, the NKC. These supplements include Alpha Lipoic Acid, Arabinoxylin, Curcumin, Garlic, Genistein, Ginseng, Lentinan, Mistletoe, N-Acetylcysteine, Resveratrol, Selenium, Vitamin B, Vitamin C, Vitamin D3, Vitamin E and zinc.
\end{abstract}

Keywords: Natural Killer Cell; Morphology; Supplements; Immunity

\section{Introduction}

One of the primary objectives of immune system stimulation is to increase the number and vitality of Natural Killer Cells (NKC). These immune cells have been shown to attack cancer cells and cells infected by viruses. NKC destroy their targets by releasing substances that damage the offending cell, leading to an immune response that eliminates the cell. If NKC target and destroy cancer cells, why does cancer exist? Large enough numbers of NKC are activated to a level required for a potent antimalignancy action. Virtually every immunology book supports that NK cells will seek and destroy mutated cells to prevent cancer.

This reviewwas performed to apply the use of supplements in the enhancement of NKC in human cancers and to develop human health and well-being. NKC program the destruction of cancer and/or virally infected cells within minutes after cell contact without causing damage to themselves or bystander cells. The death of the target cell occurs after the release of cytoplasmic granules from the effector cell [1]. These granules contain the poreforming protein perforin and serine proteases (granzymes). One mechanism of killing involves exocytosis of granules containing serine proteases and perforin [2]. A summary based on our research since 1971 and others is depicted in an animation of the mechanism of recogni- tion and destruction of target cells by the NKC [3] by Kyle Thornthwaite, Medical Animator.

\section{Historical Perspectives: Natural Killer Cells}

While conducting thesis research under Dr. Robert Leif from Florida State University in late 1971 at the Papanicolaou Cancer Research Institute in Miami, Dr. Thornthwaite's thesis project was to transform the Agar-based Jerne Plaque Assay into a non-agar setting. This immunological technique was used to detect murine B cells producing IgM against Sheep Red Blood Cells (SRBC), which were derived from the spleens of mice immunized four days earlier with SRBC. This method, termed the Plaque Cytogram Assay (PCA) [4] is able to create cell monolayers on microscope slides through centrifugation in a centrifuge bucket designed to form a glass slide bottom, whereby monolayers of cells distribute themselves onto a slide surface by centrifugation. This technique also enabled the carefully extraction of supernatants, while subsequently being able to carefully layer solutions such as guinea pig complement and Glutaraldehyde without disturbing the cell monolayer. After the cells were fixed to the slides, the samples could be processed for Light, Scanning Electron Microscopy (SEM) and Transmission Electronic Microscopy (TEM) [5-8] as 
presented below. Figure 1 shows by SEM two antibody secreting B-cells forming plaques formed due to the radial release of $\operatorname{IgM}$ antibodies in thepresence of guinea pig complement $\left(30 \mathrm{~min}\right.$ at $\left.37^{\circ} \mathrm{C}\right)$ are shown.

The Membrane Attack Complex action results in the deflated balloon appearance of the IgM-complement lysed SRBC. These lysed SRBC are also negative for Hemoglobulin as determined by Benzidine staining $[5,6]$.

Since a SRBC monolayer was being produced on the microscope slide surface, immune cellular interactions could be seen with great accuracy. One of the unusual plaques that were being formed in these immunized mice is shown in Figure 2 where lysed SRBC were not seen in the plaques. In fact, the plaques appeared "clear" by SEM (Figure 2) and light microscopy (Figure 3), where the central cell was releasing a lytic agent that completely destroyed the surrounding SRBCs in a radial fashion [4-6,9-11]. These clear plaques were seen regardless if complement was present or not, thus receiving

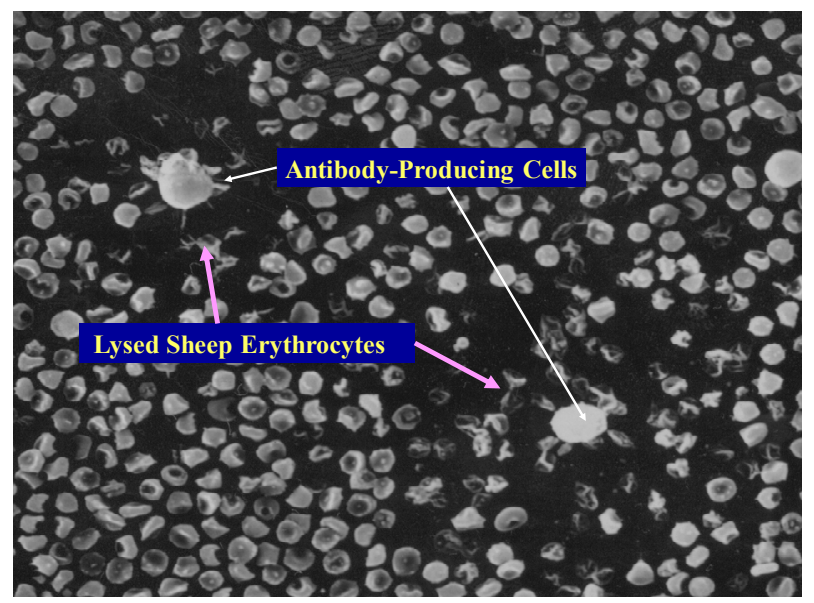

(a)

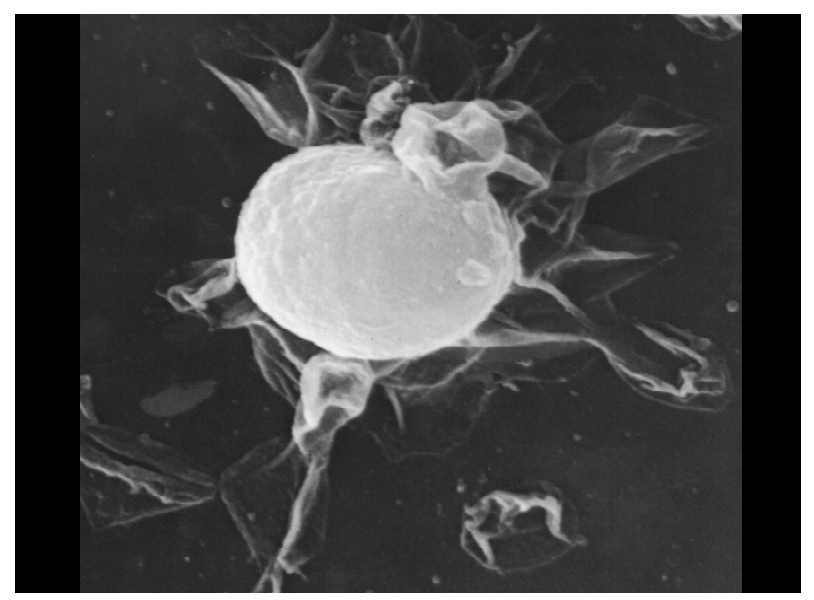

(b)

Figure 1. Two B-cell releasing IgM against SRBCs in the presence of complement. Lysed SRBC appear as deflated balloons. Copyright 1974 the American Association of Immunologists, Inc.

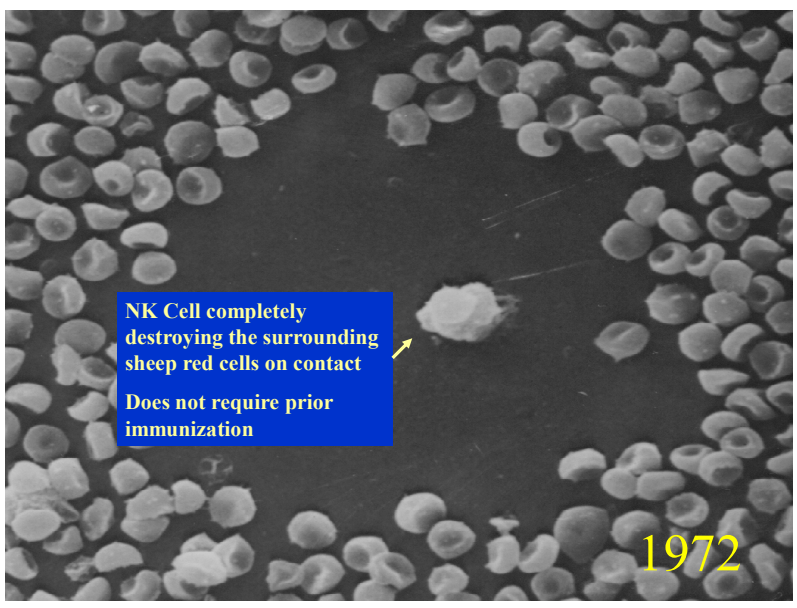

Figure 2. Natural Killer Cell (CIPFC) completely destroying the surrounding SRBC. Copyright 1974 the American Association of Immunologists, Inc.

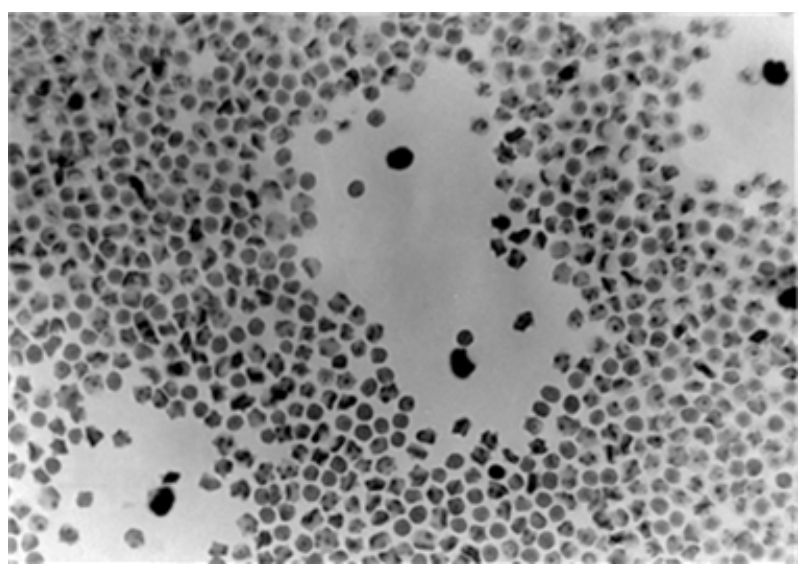

Figure 3. BSA continuous isotonic gradient enrichment showing four NKC clear plaques, where the SRBC were completely destroyed. Stained with Benzidine and Giemsa dyes.

the initial name Complement Independent Plaque Forming Cells (CIPFC). These CIPFC were seen even in the spleens and lymph nodes of non-immunized mice [4]. The CIPFC were enumerated as being about $10 \%-15 \%$ of the lymphoid population in non-immunized mice and were enriched using Bovine Serum Albumin (BSA) continuous, isotonic gradients (Figure 3) $[5,6,9,10]$.

Later in 1975 [12,13], these CIPFC were called Natural Killer Cells (NKC). In order to visualize NKC destroying cancer cells, DBA/2 mice were peritoneally injected with P815 mastocytoma cells, and lymph nodes derived from these DBA/2 mice. A monolayer of cancer cells were centrifuged onto restricted areas of a microscope slide with a dilute mixture of syngeneic lymph nodes cells using the PCA and incubated at $37^{\circ} \mathrm{C}$ for 30 minutes. In order to document the NKC activity in killing the cancer cells, a method was developed to detect killed cells by the Alcian Blue dye $[5,6]$. Alcian Blue stains dead cells that were fixed prior to Glutaraldehyde fixa- 
tion, but does not stain cells that were viable before Glutaraldehyde fixation [5-8]. Figure 4 shows the results of the incubation of NKC with target P815 cancer cells. The monolayer of cancer cells were uniform (Figure 4(a)) and potential NKC cells were seen binding to dead cancer cells (Figure 4(b)). However, the most direct proof was seen when the killing occurred, which caused a "blebbing" of the target cancer cell membranes as the result of the NKC (Figure 4(c)).

In order to obtain the smallest possible enface section that included only the NKC activity, Alcian Blue staining revealed as an area of reference where the killing was taking place. Figure 5 shows an example of the P815 villous surface (Figure 5(a)) and the "blebbing" destructtion of the P815 cancer cells by SEM (Figure 5(b)). The TEM a typical P815 cancer cell is shown in Figure 6(a), while Figure 6(b) shows the "fangs" from the NKC injecting the lymphotoxin into the P815 cancer cell with subsequent "blebbing" destruction of the cancer cell.

The term "Natural" Killer Cell was first used by Kiessling and Wigzell in a two part publications in 1975 $[12,13]$. Later, the term was used routinely in later publications [14,15]. Publications in 1975 are generally given credit for the NKC's ability to kill tumor cells $[10,16,17]$ as reviewed for example by Herbeman and Holden in 1978 [18], Herberman and Ortaldo in 1981 [19] and Heberman [20] in 2002. Ultrastrucural studies of supposed NKCs were attempted in 1979 [21]. During these times, all of the functional evidence for any "natural" activity was (and still is) measured by the ability of unimmunized lymphocytes to kill radioactively labeled tumor cells and release ${ }^{51} \mathrm{Cr}$ [12-20], which can have high background counts making the standardization of the background versus the effects of non-immunized lymphocytes (NKC activity) difficult to measure.

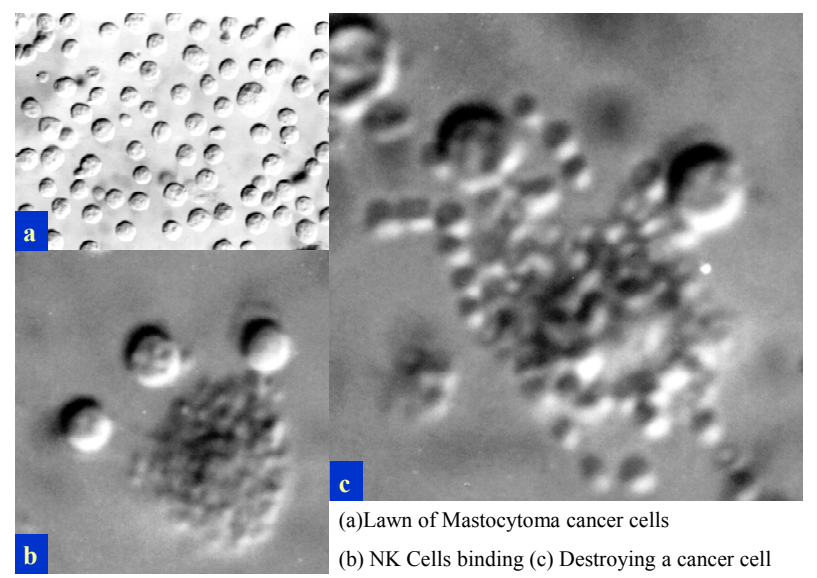

Figure 4. Nomarski optics visualization of the "blebbing effect" of the NKC damage to the P815 cancer cell membranes. The NKC were derived from lymph nodes of mice bearing the $\mathbf{P 8 1 5}$ cancer cells.

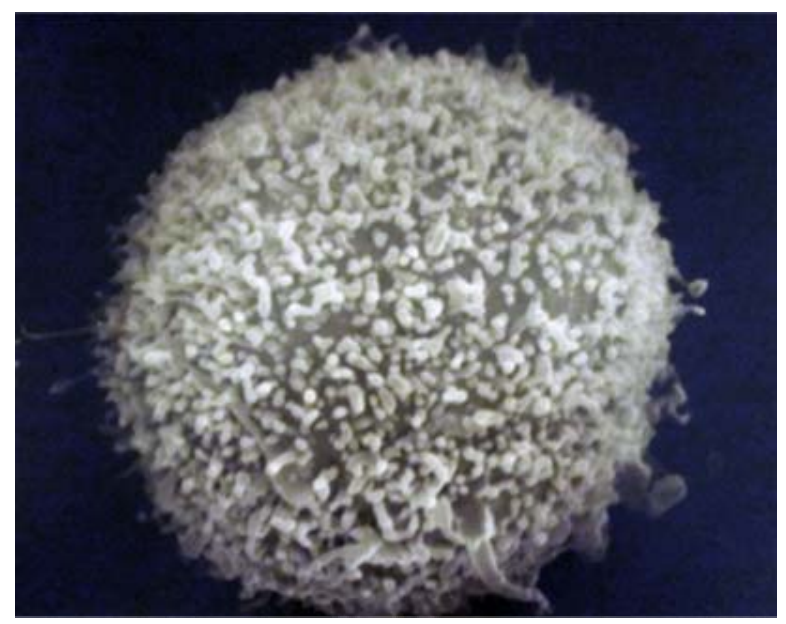

(a)

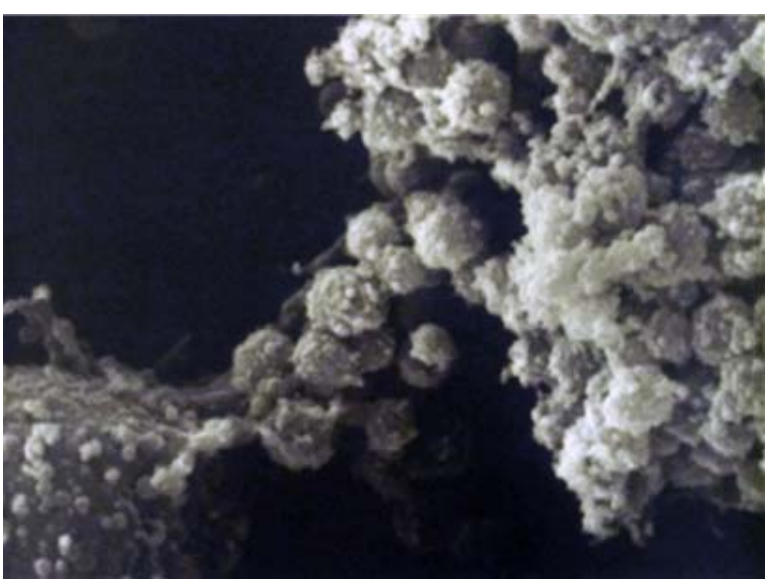

(b)

Figure 5. SEM normal villous surface of the P815 cancer cell (Figure 5(a)) and the killing of the P815 cancer cell by the injection of the NKC toxin with resulting "blebbing" of the cancer cell membrane (Figure 5(b)).

Since the discovery of the $\mathrm{NKC}$, as observed by Nomarski optics, SEM and TEM, and enumerated and enriched using BSA continuous gradients, we have been interested in using these $\mathrm{NKC}$ to effectively kill cancer cells. Besides showing the early research with $\mathrm{NKC}$, the subsequent purpose of this review is to present at least 16 components we have identified that enhance or may enhance, based on their immune modulator activity, the NKC. Our experience with the pharmacological development of the Formulation (theformulation.com) will allow us to develop a "NKC tablet" of components that may act synergistically to enhance the NKC activity as a preventative and treatment of existing cancer conditions.

\section{Supplements to Enhance NKC Activity}

\subsection{Alpha-Lipoic Acid (ALA)}

Abnormal regulation of the inflammatory response is an 


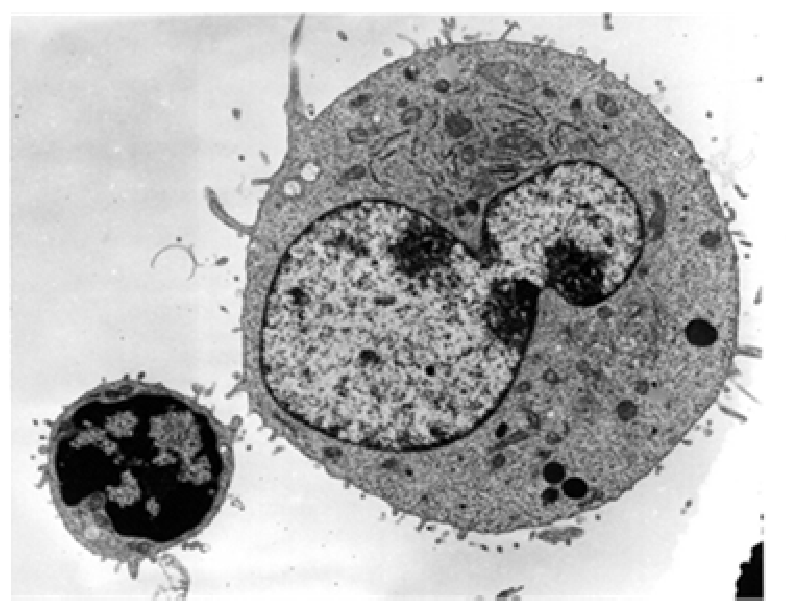

(a)

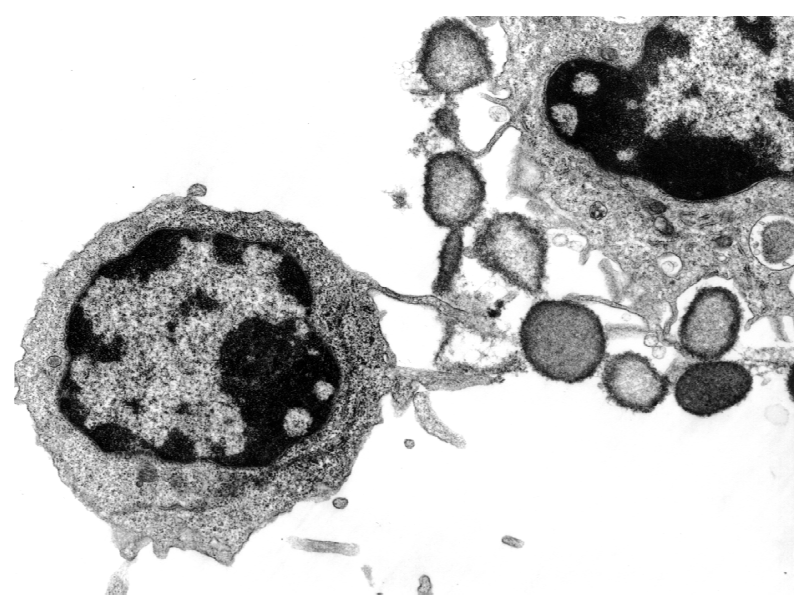

(b)

Figure 6. TEM sequence of events showing a presumptive NKC approaching the cancer cell (Figure 6(a)) and the killing of the cancer cell by the injection of the toxin with resulting "blebbing" of the cancer cell membrane (Figure 6(b)).

important component of diseases such as diabetes, Alzheimer's disease and multiple sclerosis (MS). Alpha Lipoic acid (ALA), naturally produced in the body and found in red meat, has been shown to have antioxidant and anti-inflammatory properties and is being pursued as a therapy for these diseases.Oral administration of ALA in vivo resultsin significant increases in cAMP concentration. The anti-inflammatory effects of ALA are mediated in part by the cAMP/PKA signaling cascade. These novel findings enhance the understanding of the mechanisms of action of ALA [22]. Suppressed interleukin (IL)-12/IL18 induced IFNgamma secretion and cytotoxicity in NKCs. These unusual findings suggest that ALA may actual inhibit NKC function via the cAMP signaling pathway [23]. However, the importance of ALA in T cell migration [24] and NKC activity [25] has been shown.

The anti-oxidant ALA potently suppresses clinical and pathologic disease in the animal model of multiple scle- rosis, experimental autoimmune encephalomyelitis, by inhibiting the migration of pathogenic $\mathrm{T}$ cells to the spinal cord [24]. Filatova, et al. (2009) showed increase sensitivity with two antioxidants, ALA and NAC against 3T3-SV40 fibroblasts with increased lytic activity of $\mathrm{NKC}[25]$.

\subsection{Arabinoxylan}

Population studies show that greater red and processed meat consumption increases colorectal cancer risk, whereas dietary fiber is protective [26,27]. The noncellulosic polysaccharides present in cereals $(2 \%-8 \%)$ are mostly Arabinoxylans, $(1 \rightarrow 3),(1 \rightarrow 4)$-beta-glucans, pectins and arabinogalactans. Of these, the arabinoxylans are known to absorb large amounts of water and influence significantly the water balance and rheological properties of dough. Isolation, purification, characterization, structural elucidation, functional, and nutritional attributes of cereal heteroxylans particularly the enzymatically modified Arabinoxylin from rice bran. Arabinoxylan rice bran (Biobran) is a potent biological responsemodifier (BRM) that activates NKC [28]. Biobranstimulated dendritic cells (DCs) induced CD4+ T cell proliferation and their production of cytokines, IFN-gamma, IL-10, IL-17. Results suggested that Biobran functions as a natural adjuvant for DC activation and thus may be used in DCbased vaccine strategies against infections and cancer [29]. The synergistic apoptotic potential of Arabinoxylan rice bran (MGN-3/Biobran) and Curcumin (turmeric) on a human multiple myeloma (MM) cell line U266 has been shown and may establish the foundation for in vivo studies that could have therapeutic implications [30]. Biobran enhances the effects of interventional therapies for the treatment of hepatocellular carcinoma as shown in a three-year randomized clinical trial [31]. The antitumor activity of wheat bran Arabinoxylans may also be mediated via the improvement in the immune response [32]. Arabinoxylan-oligosaccharides reduce preneoplastic lesions in the colon of rats that were treated with 1,2-dimethylhydrazine and suggest a chemopreventive effect on colon carcinogenesis that should be confirmed in a longterm carcinogenesis experiment [33]. BioBran was tested for its possible effects on in vitro maturation of human dendritic cells (DC). It is a potent enhancer of DC maturation and suggests that BioBran might be useful to create the environment that favors DC maturation [34]. Biobran induced oncostatic activity by modulating lipid peroxidation, augmenting the antioxidant defense system and protecting against oxidative stress [35]. Data also showed that nontumor-bearing mice intramuscularly injected with Biobran resulted in a twofold increase in NKC activityshowing clinical implications for the treatment of solid cancers [36]. Gollapudi and Ghoneum demonstrated that Biobran is an effective chemo-sensitizer 
and may represent a potential novel adjuvant for the treatment of breast cancer [37]. Both wheat bran Arabinoxylans and gut flora-mediated fermentation products protect human colon cells from genotoxic activities of 4-hydroxynonenal and hydrogen peroxide [38]. Breast cancer cell lines undergo apoptosis following phagocytesis of $S$. cerevisiae. Biobran has been shown to enhance this effect [39]. Hydrolyzed water-soluble corn husk Arabinoxylan has the ability to increase the level of immunopotentiating activity without causing over response of immunological reaction even if it is administrated orally to mice [40]. Hydrolyzed Rice Bran was shown to be useful in reducing the physical stress associated with acute respiratory tract infection [41]. Biobran enhances murine $\mathrm{NKC}$ activity of aged mice and may be useful for enhancing NKC function in aged humans [42]. Biobran is a potent activator of human $\mathrm{NKC}$ function in vivo and in vitro [43].

\subsection{Curcumin}

Based on basic science research and suggestive ecologic level data on cancer incidence and spice consumption, improving epidemiologic assessment of this potentially chemopreventive food item derived from the spice, Curry, may enhance the understanding of diet and cancer risk [44]. Urothelial carcinoma has the highest lifetime treatment cost of any cancer, making it an ideal target for preventative therapies. There is increasing evidence to suggest that many degenerative or pathological processes, such as aging, cancer, and coronary heart disease, are related to reactive oxygen species and radical-mediated reactions. Inflammation plays a major role in the development of various neurodegenerative diseases, including Alzheimer's disease, Parkinson's disease, multiple sclerosis, brain tumor, and meningitis, the incidence of certain neurodegenerative diseases among people living in the Asian subcontinent, where people regularly consume spices, is much lower than in countries of the western world. Extensive research over the last 10 years has indicated that nutraceuticals derived from such spices as turmeric, red pepper, black pepper, licorice, clove, ginger, garlic, coriander, and cinnamon target inflammatory pathways, thereby may prevent neurodegenerative diseases [45]. Bioactive components of many foods added during cooking have potential antioxidant, anti-inflammatory, antimicrobial, antibacterial and chemopreventive properties. India has some of the highest spice consumption in the world, among 3625 participants in the India Health Study. An important characteristic of cancer is that at some point in their development, they overcome the suppression of the immune system. Curcumin reverses breast cancer mediated suppression of NKC cytotoxicity [46]. Curcumin also been shown to be very effective against malignant melanoma which normally has a response rate of only $10 \%-15 \%$ [47]. Curcumin induces proapoptotic effects in human melanoma cells, and modulates the cytokines. Nitric oxide (NO) production by immune cells showed an initial downregulation of Th1 cytokine response and NO production by macrophages, and their upregulation in NKC, which picked-up upon prolonged treatment with Curcumin, culminating in a stronger tumoricidal effect [48]. Curcumin is a very effective chemopreventive therapeutic agent [49]. Extensive research has addressed the chemotherapeutic potential of curcumin [50]. Curcumin can modulate the effects interferon and interleukin, which are all important in the maturation process of NKC activity. However, it is difficult to differentiate the actual effects of curcumin on the NKC activity versus the direct cytotoxic effect of curcumin on tumors cells $[46,47,49,51,52]$.

\subsection{Garlic}

Complementary and alternative medicine (CAM) use, including herbals and multivitamin supplements, is quite common in the US, and has been shown to be highest in breast cancer survivors [53]. There is an inverse association between total intake of the Allium vegetables (onions, garlic, shallots, leeks, chives, etc.) and risk of intestinal gastric cancer [54]. The chemopreventive effects of Allium vegetables have been studied extensively in reducing the risk for cancer risk [55]. Epidemiological observations and laboratory studies have indicated the anti-carcinogenic potential of garlic, which has been traditionally used for various human diseases around the world [56]. Garlic (Allium sativum) holds a unique position in history and is recognized for its therapeutic potential. The health promoting properties of garlic often referred to its sulfur containing metabolites, e.g. allicin and its derivatives. Garlic is useful in preventing the suppression of immune response associated with increased risk of malignancy as it stimulates the proliferation of lymphocytes, macrophage phagocytosis, stimulates the release of interleukin-2, tumor necrosis factor-alpha and interferon-gamma, and enhances NKC [57]. Aged garlic extract (AGE) has significant biological activities including immunomodulative and antioxidative effects. The number of NKCs and the NKC activity increased significantly utilizing AGE [58]. A glycoprotein with molecular weight (MW) of about $14 \mathrm{kDa}$ was isolated from garlic extract and it induced NKC augmentation against a K562 tumor cell line [58].

Garlic may be useful in preventing the suppression of immune response that is associated with an increased risk of malignancy. Garlic can detoxify chemical carcinogens and may directly inhibit the growth of cancer cells [59]. Garlic stimulates the proliferation of macrophages and lymphocytes and protects against the suppression of immunity by chemotherapy and ultraviolet radiation [60]. 
NKC cytotoxic activities were evaluated by Hassan et al. in which four garlic preparations significantly enhanced NKC and killer cell activities of the spleen cells of tumorbearing mice [61]. Only AGE inhibited the growth of inoculated tumor cells. These results suggest that different types of garlic preparations have different pharmacologic properties, and among the four garlic preparations studied, AGE gave the best anticancer response [62]. These studies strongly suggest that AGE could be a promising candidate as an immune modifier [63]. In order to study the effect and mechanism of garlic on preventing oral precancer, 32 Wistar rats were randomly divided into two groups. The garlic group was painted with garlic solution on the hard palatal mucosae. The control group was applied with distilled water that is equal in quantity. Then, chemical carcinogen 4-nitroquinoline 1-oxide (4NQO) was painted on the same sites for both groups, three times weekly. The results revealed that garlic effectively prevented oral precancer induced by 4 NQO. This effect may be related to the following factors that garlic can improve the activation of NKCs, the function of T-lymphocytes, and the level [64]. Fraction $4(\mathrm{~F} 4)$, a protein fraction isolated from aged garlic extract, enhanced cytotoxicity of human peripheral blood lymphocytes (PBL) against both natural-killer (NKC)sensitive K562 and NKC-resistant M14 cell lines.

Of the many beneficial actions of garlic, inhibition of the growth of cancer may be the most important. Kim, Bommareddy and Singh have shown that garlic constituent diallyl trisulfide (DATS) inhibits growth of cultured and xenografted human prostate cancer cells in association with apoptosis induction [65]. They indicated that the DATS-induced apoptosis in prostate cancer cells is mediated in part by suppression of X-linked inhibitor of apoptosis (XIAP) protein expression, and that XIAP represents a viable biomarker of DATS. Diallyl sulfide (DAS), one of the main active constituents of garlic, causes growth inhibition of cancer cells in vitro and promotes immune responses in vivo in experimental settings. The study by $\mathrm{Wu}$ et al. revealed that DAS significantly inhibits the growth and induces apoptosis of human cervical cancer HeLa cells in vitro [66-68]. S-allylcysteine (SAC), a sulfur containing amino acid derived from garlic, has been reported to have antioxidant, anticancer, anti-hepatotoxic and neurotrophic activity. This study concludes that intervention of SAC could prevent free radicals associated deterioration of cognitive functions and neurobehavioral activities [69]. Morioka et al., found that F4 is a very efficient immunopotentiator and may be used for immunotherapy [70]. Allicin, the main flavor compound in garlic, has anti-carcinogenic activities in a range of cancer cells [71]. DATS is a garlic organosulfide that is toxic to cancer cells. At the doses evaluated, DATS appears to be an effective attenuator of $\mathrm{BaP}-i n d u c e d$ breast carcinogenesis, in vitro [72]. Diallyl disulfide (DADS) is a major organosulfur compound derived from garlic, gastric adenocarcinoma cell line at various concentrations. DADS decreasesthe viability of AGS cell lines and inducesapoptosis in a dose-dependent manner [73-75]. SAC was identified as a potent compound derived from garlic. This study demonstrated the chemo preventive activity of SAC in vitro, and that SAC may be a promising candidate for prostate cancer treatment in which natural allyl sulfur compounds show antiproliferative effects on tumor cells [76].

Garlic extracts exert anti-cancer and anti-inflammatory effects through antioxidant mechanism [77]. Morihara et al. examined the effectiveness of AGE, a garlic preparation rich in water-soluble cysteinyl moieties, and its component for scavenging of superoxide by using the hypoxanthinexanthenes oxidase and human neutrophils [78]. Aged garlic extract $(3 \mathrm{mg} / \mathrm{ml})$ significantly inhibited superoxide production, suggest that aged garlic extract may be useful for preventing diseases associated with reactive oxygen species. Their studies showed that DATS induced apoptosis in human colon cancer HT29 and in colon 205 cell lines in vitro. Findings indicated that DATS inhibits tumor growth in an allograft animal model. Thus, DATS may represent a colon cancer preventive agent and can be used in the future [66-68]. Medicinal benefits of Allium vegetables, such as garlic, have been noted throughout recorded history, including protection against cancer and cardiovascular disease. Powolny et al. data suggest that DATS is able to increase worm lifespan by enhancing the function of the prolongevity transcription factor skn-1 [79]. The antitumor properties of water-soluble sulfur compounds may play a relevant role in the formation of both reduced glutathione conjugates and radical species that affect the activity of the thiol-proteins involved in fundamental cellular processes [80]. Report showed that the aqueous garlic extract S-allylcysteine (SAC) inhibited the epithelial-mesenchymal transition (EMT) of human oral cancer CAL-27 cells in vitro. It was shown that $\mathrm{SAC}$ has potential as an agent against tumor growth and the progression of oral cancer [81].

Hydrogen sulfide $\left(\mathrm{H}_{2} \mathrm{~S}\right)$ is a novel gasotransmitter that regulates cell proliferation and other cellular functions. Sulforaphane (SFN) is a sulfur-containing compound that exhibits anticancer properties, and young sprouts of broccoli are particularly rich in SFN. A $\mathrm{H}_{2} \mathrm{~S}$-releasing diet or drug might be beneficial in the treatment of prostate cancer [82].

There is mounting evidence that aged black garlic extracts (ABGE) possess significant anticancer actions. The anticancer action of ABGE may be partly due to its antioxidant and immunomodulative effects [83-85]. A major contributing factor to the prevention of colon cancer is in the use of dietary constituents, such as Garlic oil to pre- 
vent the development of colorectal cancer [86,87]. Garlic phytochemicals influence the pharmacokinetic and pharmacodynamic behavior of concomitantly ingested drugs [88]. Garlic consumption not only causes increased energy demand from the faster RBC turnover but also increases the production of $\mathrm{CO}$, a pleiotropic gasotransmitter, which in turn stimulates splenic erythropoiesis by an erythropoietin-independent mechanism, thus completing the sequence of feedback regulation for $\mathrm{RBC}$ metabolism. Being a pleiotropic gasotransmitter, $\mathrm{CO}$ may be a second messenger for garlic's other physiological effects [89]. The scavenging capacity of reactive oxygen species, such as hydroxyl radicals, is reported not to decrease in boiled garlic. These findings indicate a promising potential for the use of garlic-derived sulfur compounds in chemoprevention and chemotherapy [90]. Garlic and garlic-derived compounds reduce the development of mammary cancer in animals and suppress the growth of human breast cancer cells in culture. Ma et al. reported that 14.7-year follow-up for gastric cancer incidence and cause-specific mortality among 3365 randomly assigned subjects in this masked factorial placebo-controlled trial [91-93]. Garlic and vitamin treatments were associated with non-statistically significant reductions in gastric cancer incidence and mortality. Vitamin treatment was associated with statistically significantly fewer deaths from gastric or esophageal cancer, a secondary endpoint $(p=0.014)$. Health benefits of garlic and other Allium vegetables (e.g., onions), such as lipid lowering and anticancer effects, are credited to metabolic byproducts, including DATS. Known pharmacological responses to this natural product include alteration in carcinogen-metabolizing enzymes, cell cycle arrest, induction of apoptotic cell death, suppression of oncogenic signal transduction pathways, and inhibition of neoangiogenesis [94]. The mechanism of biological action of garlic-derived sulfur compounds in human hepatoma (HepG2) cells can be dependent on the presence of labile sulfane sulfur in their molecules, thereby, influencing transmission of signals regulating cell proliferation and apoptosis [95].

Fresh garlic has the highest content of bioactive components and the greatest anticancer efficacy [96]. Walter et al. indicated that the use of garlic and grape seed may be associated with reduced risk of hematologic malignnancies [97]. S-allylmercaptocysteine (SAMC), one of the water-soluble organosulfur garlic derivatives, has been demonstrated as a suppressive agent against some tumors. The effects of SAMC on the proliferation and metastasis of colorectal cancer (CRC) under in vitro and in vivo conditions were evaluated.

Taken together, the proliferation and metastasis of CRC cells can be significantly suppressed by SAMC treatment under both in vitro and in vivo conditions.
SAMC may thus be a promising candidate for CRC chemotherapy [98].

The Allylmercapto glutathione S-conjugate, S-allylmercapto-L-cysteine (SAMC) is biotransformed from allyl sulfides and from naturally occurring water-soluble garlic derivatives. The results from Lee et al. suggested that SAMC may regulate bcl-2 and bax to induce apoptosis in transplanted tumor cells [73-75]. Further studies should be conducted to establish the clinical expediency of malignant neuroblastomas in humans [99].

Diallyl disulfide (DADS), a sulfur compound derived from garlic, has been shown to have protective effects against colon carcinogenesis in several studies performed in rodent models. DADS showed anti-proliferative effects on colon cancer HT-29 cells, and DHDG and DHUG genes were found to be involved in this process [100]. SAMC-induced apoptosis is associated with the Id-1 pathway, and that the inactivation of Id-1 enhances the ability of SAMC to inhibit the survival, invasion and migration of bladder cancer cells [101].

Garlic reduces the side effects caused by anti-cancer agents. Thus, garlic and garlic-derived compounds are promising candidates for breast cancer control [102]. The ability of garlic preparations to inhibit cancer cell-growth has been attributed to a group of structurally-related organosulfur compounds found in the crushed clove [103]. For many years, in vitro and in vivo studies have reported that organosulfur compounds (OSCs), naturally found in Allium vegetables are able to suppress the proliferation of various tumor cells. Furthermore, growth of both sensitive (MCF-7) and resistant (Vcr-R) human breast carcinoma cells was significantly decreased by these tetrasulfides. The observed antiproliferative effect appeared to be associated with a G2-M cell cycle arrest [104]. There is a body of evidence showing that several lifestyle and dietary factors are associated with colorectal polyps' formation [105]. Garlic (Allium sativum) has been valued in many cultures both for its health effects and as a culinary flavor enhancer. Garlic's chemical complexity is widely thought to be the source of its many health benefits, which include, but are not limited to, anti-platelet, pro-circulatory, anti-inflammatory, anti-apoptotic, neuroprotective, and anti-cancer effects. While a growing body of scientific evidence strongly upholds the herb's broad and potent capacity to influence health, the common mechanisms underlying these diverse effects remain disjointed and relatively poorly understood. Boiled garlic powder (BGP) may exert chemopreventive effects against colon carcinogenesis at least in the initiation stage [106]. Epidemiological studies iNKC increased garlic (Allium sativum) consumption with a reduced incidence of cancer in various human populations

Garlic also induced apoptosis, and this was associated with an increase in caspase 3 activity [107]. The associa- 
tion between diet and prostate cancer (PC) risk, although suggestive, still remains largely elusive particularly in the Asian population. In 194 cases with PC and 317 controls, that total fat may increase $\mathrm{PC}$ risk and tomatoes/tomato products and garlic may protect patients against PC [108]. Cardiovascular diseases and cancer are the leading causes of death in most countries. These diseases share many common risk factors as well as pathogenetic determinants, and their incidence is related to age in an exponential manner. Mechanisms responsible for the cardiotoxicity of anticancer drugs, the possibility to prevent them and provide examples of diet-derived phytochemicals and other biological substances that could be exploited for protecting the cardiovascular system according to a joint cardio-oncological preventative approach [109].

Alzheimer's disease (AD) is the most common form of dementia in the older people and 7th leading cause of death in the United States. Thus, based on the reported positive preliminary results reviewed, further research is required to develop the full potential of "Aged Garlic Extract" (AGE) and/or SAC into an effective preventative strategy for AD [110]. Diallyl sulfide (DAS), diallyl disulfide (DADS), and diallyl trisulfide (DATS) are major organosulfur compounds exiting in garlic (Allium sativum). These studies demonstrate that application of DAS, DADS, and DATS might serve as potential antimetastatic drugs [111]. There is strong evidence from studies of prostate cancer cell lines and rodent models that several garlic derivatives may have anti-inflammatory, antioxidant, or other anticancer properties. These derivatives include DAS, DADS, DATS and ajoene which show these to be promising anticancer agents in oncohematology [112].

OSCs derived from plants, fungi or bacteria can serve as chemopreventive and/or chemotherapeutic agents and have been attracting medical and research interest as a promising source for novel anti-cancer agents. Amphotericin $\mathrm{B}(\mathrm{AmB})$, a classical antifungal drug is limited by its side effects and the emergence of drug-resistant strains. The enhancing effect of allicin is dependent on the inhibition of ergosterol-trafficking from the plasma membrane to the vacuole membrane, which is considered to be a cellular response to protect against disintegration of the vacuole membrane. Allicin found in crushed garlic acts synergistically with $\mathrm{AmB}$ and the synergistic fungicidal activities of $\mathrm{AmB}$ and allicin may have significant implications for the development of vacuole-targeting chemotherapy against fungal infections [113].

\subsection{Genistein}

Genistein (GEN), the active component of Soy, stimulates antiangiogenesis components, and its estrogen like structure would warrant it having immune modulating activity that would involve NKC stimulation [114]. Exposure to GEN in a rat model increased the percentages helper and cytotoxic T cells [115].

Epidemiological studies have suggested that populations with high isoflavone intake through soy consumption have lower rates of breast, prostate, and colon cancer. Isoflavone GEN in soybean is considered a potent chemopreventive agent against cancer as copper levels are known to be considerably elevated in almost all types of cancers. Ullah et al. in 2011 showed that GEN is able to target endogenous copper leading to pro-oxidant signaling and consequent cell death and explains why GEN has apreferential cytotoxicity towards cancer cells [116].

Furthermore, GEN is considered to exert potent antitumor effect partially through its anti-angiogenesis property. GEN exerts its anti-cancer effects by inhibiting protein tyrosine kinase that is involved in up-regulation of VEGF. Zhou et al. in 2012 provided an experimental basis for combined use of ATRA and GEN in the treatment of lung cancer [117]. The inhibition of protein tyrosine kinase (PTK) activity and MAPK activation and the decrease in matrix metalloproteinases (MMPs) production and activity by GEN interrupt VEGF-stimulated endothelial cell activation, which thereby may represent a mechanism that would explain the anti-angiogenesis effect of GEN and its cancer-protective function [118]. Genistein aglycone might be an effective alternative therapy for the management of age-related skin changes in postmenopausal women [119]. GEN reduced human colon cancer cell line DLD-1 cell viability and increased apoptosis [120].

In breast cancer, the interaction between estrogenproducing breast adipose fibroblasts (BAFs) and estrogen-dependent epithelial tumor cells is pivotal. Local estrogen production is catalyzed by aromatase, which is differentially regulated in disease-free and tumorigenic breast tissue. The use of aromatase inhibitors to block local estrogen production has been proven to beeffective in treatment of estrogen-dependent breast cancer [121]. Worldwide geographical variation in cancer incidence indicates a correlation between dietary habits and cancer risk.

In several cancer types, expression of multidrug resistance (MDR) proteins has been associated with lack of chemotherapy response. In advanced prostate cancer (PCa) the use of chemotherapy is mainly palliative due to its high resistance [122]. Soy consumption is associated with a lower incidence of colon cancer. These novel anti-proliferative mechanisms of GEN suggest a possible role of combining GEN with other chemoreceptive agents for the treatment of colon cancer [123]. GEN possesses a structure similar to estrogen and can both mimic and antagonize estrogen effects although at high concentrations it inhibits breast cancer cell proliferation [114]. 
GEN possessesanti-cancer, anti-inflammatory, anti-oxidant and anti-osteoporosis effects that may be a promising drug to inhibit the inflammatory process and prevent liver damage in patients with non-alcoholic steatohepatitis [124]. Cancer cells require high levels of lipid synthesis to produce structural, signaling and energetic lipids to support continuous replication. Lipogenesis can occur mainly by the tandem activation of acetyl-CoA carboxylase, fatty acid synthase and stearoyl-CoA desaturase-1. Metabolic pathway is a potential anticancer target for nutritional and pharmacological interventions by globally down regulating lipid biosynthesis. GEN suppresses cancer cell growth, emphasizing the relevance of this botanical compound as a potential therapeutic agent against lung cancer, a disease for which therapeutic choices remain limited [125]. Up regulation of Brcal may be required for prepubertal dietary genistein exposure to reduce later mammary tumorigenesis, perhaps because in the absence of this up regulation, mice do not exhibit GEN-induced downregulation of estrogen receptor (ER$\alpha$ ), progesterone receptor (PgR) and $\mathrm{RaNKCl} \mathrm{[126].} \mathrm{Var-}$ ious chemopreventive compounds alter gene expression, possibly explaining their biological activity [127]. The effective activity of GEN on osteolytic bone metastasis and bone mineral was investigated. GEN could inhibit osteolytic bone metastases, suppress bone resorption, increase bone mass and improve bone microstructure in bone metastases of breast cancer [128]. Genistein and methoxychlor modulate the activity of NKCand the expression of phenotypic markers by thymocytes and splenocytes in a rat model [115]. Adult T-cell leukemia (ATL) occurs in human T-lymphotropic virus type I-infected individuals and is endemic to the southwestern area of Kyushu in Japan. GEN had cytotoxic effects on ATL cells [129]. Whether these anticancer activities involve modulation of the $\mathrm{NKC}$ remains to be investigated.

\subsection{Ginseng}

An Acidic Polysaccharide of Ginseng (APG), so called ginsan, is a purified polysaccharide. APG has multiple immunomodulatory effects of stimulating $\mathrm{NKC}$ and $\mathrm{T}$ cells and producing a variety of cytokines that diminish the proinflammatory response. APG may serve as an effective therapy for human multiple sclerosis (MS) and other autoimmune diseases [130]. Ginseng is widely used in Asian countries as a tonic to increase energy, however its efficacy for treating cancer-related fatigue has not been carefully studied [131]. Ginseng polysaccharide has certain improving immune function effect in nasopharyngeal carcinoma and in patients during radiotherapy (RT); it could also eliminate the occurred adverse reaction to RT and the general condition of patients [132].

Ginsenoside Rh2, isolated from an ethanol extract of the processed root of Panax ginseng CA Meyer, inhibits the growth of B16 melanoma cells in induction of apoptotic cells in the tumor and increases NKC activity in spleen cells from tumor-hearing nude mice [133]. Panax ginseng was shown to stimulate cellular immune function by peripheral blood mononuclear cells (PBMC) from normal individuals and patients with either the chronic fatigue or the acquired immunodeficiency syndrome. Furthermore, ginseng enhances cellular immune function of PBMC both from normal individuals and patients with depressed cellular immunity [134]. In 63 patients with stomach cancer, the results showed that the count of $\mathrm{T}$ lymphocytes in chemotherapy combined with Shenmai (ginseng preparation) injection (SMI) group increased, while in control groups it decreased. Also, activities of NKC and lymphokine activated killer cell (LAK) level increased in the SMI group [135]. The ethanol-insoluble fraction of ginseng was tested for immunomodulatory activity. These results suggest that the ethanol-insoluble fraction of ginseng shows antitumor effects by being immunomodulator of NKC activity [136]. The positive effect of Panax ginseng extracts on cell-mediated immune functions in men hasbeen shown in randomized trials [137]. The immunomodulatory activity of ginsenoside increased the number of T-helper cells with respect to the whole T-cell number and increased the splenocyte NKC activity. The pharmacological effects of ginseng is its ability to replenish vital energy, strengthen the body's immune resistance and improve memory [138].

\subsection{Lentinan}

As reviewed by Wasser, the species of mushrooms on Earth is estimated at 140,000 , yet maybe only $10 \%$ are known [139]. Mushrooms comprise a vast and yet largely untapped source of powerful new pharmaceutical products. In particular, and most importantly for modern medicine, they represent an unlimited source of polysaccharides with antitumor and immunostimulating properties. Data on mushroom polysaccharides have been collected from 651 species and 7 infraspecific taxa from 182 genera of higher Hetero- and Homobasidiomycetes. These polysaccharides are of different chemical compo- sition, with most belonging to the group of beta-glucans; these have beta- $(1 \rightarrow 3)$ linkages in the main chain of the glucan and additional beta- $(1 \rightarrow 6)$ branch points that are needed for their antitumor action. High molecular weight glucans appear to be more effective than those of low molecular weight. Most of the clinical evidence for antitumor activitycomes from the commercial polysaccharides Lentinan (LEN). LEN is especially beneficial in clinics when used in conjunction with chemotherapy. Mushroom polysaccharides prevent oncogenesis, show directantitumor activity against various allogeneic and syngeneic tumors, and prevent tumor metastasis. Poly- 
saccharides from mushrooms do not attack cancer cells directly, but produce their antitumor effects by activating different immune responses in the host. The antitumor action of polysaccharides requires an intact T-cell component; their activity is mediated through a thymus-dependent immune mechanism [140].

LEN, a polysaccharide extracted from a kind of black mushroom shiitake, has been clinically applied as an antitumor and antimetastatic drug, and has been reported to prevent both chemical and viral carcinogenesis. It is known that LEN affects the tumorous vascular system resulting in the induction of hemorrhagic necrosis which is dependent on T-cells in the tumor [140].

LEN, an antitumor polysaccharide used clinically in Japan, requires the intact $\mathrm{T}$ cell compartment to manifest its antitumor effects. These results suggest that, in addition to the augmentation of immune effectors cell activity against tumors, infiltration of these cells into the tumor, initiated by the delayed-type hypersensitivityDTH responses at tumor sites, may be involved in eradication of tumors by LEN [141,142]. NKC-mediated killing of tumor cells both in vitro and in vivo. In a combined study, Vetvicka et al. in 2008 suggested that PS3 a sulfated derivative of a $(1 \rightarrow 3)$-beta-D-glucan is similarly effective as native non-sulfated $(1 \rightarrow 3)$-beta-D-glucan and is generally more active than LEN $[143,144]$. LEN could enhance the anti-tumor immuno-reaction of Dendritic Cell Vaccine (DCV) effectively [145].

Glucans have a long history as nonspecific biological modulators. A novel glucan-Phycarine-was isolated from sporophytes of Laminaria digitata. Phycarine showed significant stimulation of phagocytic activity as well as potentiation of synthesis and release of IL-1, IL-6 and TNF-alpha. In addition, Phycarine increased NKC-mediated killing of tumor cells both in vitro and in vivo while acting via complement type 3 receptors [146]. Significant regression in tumor formation was observed in LEN fed mice compared to control (unfed) mice when K36 or human colon-carcinoma cells were used. Antitumor property of LEN was maintained with oral administration. In addition, "primed" lymphocytes, when given passively to immunodeficient mice, were able to retard the development of tumors in these mice [147]. The preoperative administration of LEN for patients undergoing cardiopulmonary bypass (CPB) ameliorated the impairment of NKC activity and promoted the rapid recovery of CD4positive cells [148].

The immunopharmacological characteristics of angelan, a polysaccharide purified from Angelica gigas Nakai, was investigated in relation to the specificity to immune cells. The treatment of angelan increased the expression of IL-2, IL-4, IL-6, and IFN-gamma. The experiment of host resistance to syngeneic tumors also showed that angelan potentiated the immune functions [149]. Han et al. studied the action of Polyporus polysaccharide (PPS), mycobacterium polysaccharide (MPS) and LEN on lymphokine-activated killer (LAK) cell activity in vitro. The three combined enhanced the LAK activity by $42 \%$ $56.9 \%$, and reduce the dose of rIL-2 needed to have the same LAK activity by $50 \%(\mathrm{p}<0.01)$. Therefore, PPS, MPS and LEN could be used as bioactivity regulators in LAK cell therapy in tumor treatment [150]. Rafique and Adachi concluded that the intraportal administration of chemotherapeutic agents reduces NKC activity in the liver and the addition of LEN prevents this reduction [151].

The usefulness of lymphocyte subset change as an indicator for predicting survival time and the effectiveness of combined treatment with an immunopotentiator, LEN, and carboplatin (CBDCA) were investigated. Changes of lymphocyte subsets of killer $\mathrm{T}$ cell/suppressor $\mathrm{T}$ cell and NKC on posttreatment compared to pre-treatment are clinically useful indicators for predicting and monitoring the effectiveness of combined treatment with LEN [152]. Twenty-one patients with malignant peritoneal or pleural effusions of gastric carcinomas were treated with intracavitary injection of LEN in which LEN enhanced the induction of cytotoxic T-lymphocytes [153]. KRN7000, a compound with a novel alpha-galactosylceramide structure significantly prolonged the lifespan of mice demonstrating that KRN7000 would be a useful agent for cancer therapy [154]. The effects of orally administered biological response modifiers (BRMs) in preventing postoperative micro liver metastasis of primary colorectal cancer were examined in experimental animals. LENsuppressed liver metastasisand prolonged the survival period. It elevated the liver NKC and liver macrophage activities [155]. The life-prolonging effect of the combination of LEN and IL-2 is mediated by antigen-specific T cells and that the combination of pre- and post-operative therapy with LEN and IL-2 may be effective to prevent cancer recurrence and metastasis after surgical resection [156]. Suzuki et al. in 1994, indicated that the antitumor effects of LEN /IL-2 are mediated by CD8 + CTL but not by $\mathrm{CD} 4+\mathrm{T}$ cells or NKC1.1 + NKC/LAK cells, and suggest that this combined therapy may be effective against even established tumors that are resistant to IL-2 therapy [141,142]. LEN markedly prevented cyclophosphamide (CY)-induced suppression and promoted the recovery of IL-2-production. LEN exhibits lightening or restorative effects on CY-induced suppression of antitumor effectors activities of murine spleen cells [157]. Thus it was shown that LAK cells stimulated with IL-2 plus Lentinan had strong cytotoxicity and might be useful as effector cells for adoptive immunotherapy Tani et al. [158] in a study of 15 patients with gastric carcinoma, peripheral blood mononuclear cells (PBM) were obtained serially before and 3, 5 and 7 days after LEN administra- 
tion. NKC activity was significantly enhanced 7 days after the drug injection [159]. The antitumor effect of LEN is due to the activation of killer cells in vivo, because the optimal concentration of LEN for the induction of killer cells in vitro was equivalent to the plasma concentration obtained after clinical doses of this agent [160]. Lymphocyte subpopulations of the spleen were assayed in 26 patients with gastric cancer and 5 patients with benign disease using two-color flow cytometric analysis. The above results suggest that lymphocyte subpopulations in the spleen may have more immunosuppressive potential in proportion with the stage of gastric cancer, but that this reduced immune state may be altered when LEN was given to these patients [161]. When gastric cancer patients were pretreated with BRM, such as Lentinan, LAK cells from PBMC showed higher NKCand LAK activities as compared with those of patients without BRM pretreatment [162]. Twenty effusions in sixteen patients with malignant peritoneal and/or pleural effusions were treated with intracavitary injection of LEN in which lymphokine activated killer activity were also augmented or maintained after LEN injection [163]. The usefulness of Lentinan, as an agent for postoperative adjuvant therapy, was investigated in patients with gastrointestinal cancer [164]. LEN had a marked immunopotentiating efficacy in the stage IV gastrointestinal cancer patients. There is clinical application of a combination of LEN and IL-2 for immunotherapy against cancer without detrimental side effects [165]. The adoptive transfer of LAK cells combined with intraperitoneal administration of both recombinant interleukin-2 (rIL-2) and LEN markedly inhibited the growth of the endometrial tumor cell line HHUA xenografts in nude mice, while no response was observed in nude mice treated with LAK cells plus either recombinant (rIL-2) or LEN, or treated with rIL-2 plus LEN alone. These results suggest the clinical application of adoptive immunotherapy in association with LAK cells, rIL-2, and LEN as a treatment of gynecologic cancers [166]. These results indicate that intrapleural Lentinan administration is a useful treatment for carcinomatous pleuritis and peritonitis [167]. IL-2 and LEN in combination are more effective than either one alone for inducing destruction of pulmonary metastases [168]. Endoscopic intratumoral injection of LEN may enhance local and systemic immunity in patients with gastric cancer [169]. The in vitro effects of LEN on NKC, antibody-dependent cell-mediated cytotoxicity (ADCC), lectin-dependent cell-mediated cytotoxicity (LD$\mathrm{CC}$ ) and mitogen-induced blast transformation were studied in patients with solid tumors and chronic lymphocyte leukemia (CLL). LEN increased natural cell-mediated cytotoxicity (NCMC) of tumor-bearing subjects. The most prominent enhancement of NKC and ADCC activity was seen in CLL patients, where a dose-related increase was seen (from 0.01 to $1 \mathrm{microgram} / \mathrm{ml}$ ) [170]. Gastric cancer patients treated with chemotherapy with or without LEN, were showed excellent end-point results only in Lentinan-administered patients with normal protein levels was seen [171].

The interferon level in the peripheral blood circulation of cancer patients was elevated $12 \mathrm{~h}$ following LEN administration, and NKC activity of peripheral mononuclear cells was enhancedin $48 \mathrm{~h}$. These data indicate that LEN favorably affects the host mechanisms of man [172]. In patients with cancer of digestive organs, NKCactivity and PHA induced blast response for lymphocytes increased significantly. Cancer patients $(n=11)$ received LEN i.v. $2 \mathrm{mg}$, NKC activity of lymphocytes was increased in four patients on the following day [173]. These results concluded that LEN ispromising as a new type of polysaccharide immunoadjuvants useful for cancer chemotherapy [174] where chemotherapy alone has shown little antitumor activity against advanced oral squamous cell carcinoma (OSCC) patients.

LEN administration was shown to be effective against OSCC and has the potential of being a new therapeutic tool for future treatment of these tumors [175]. Combination of LEN with standards of care in acute myeloid leukemia, idarubicin, and cytarabine increased average survival compared with monotherapy and reduced cachexia [176]. LEN is efficient in promoting chemosensitivity in colon carcinoma cells, has much less side effects, and has great potential to be applied as a supplement for colon cancer therapy $[177,178]$.

Complementary alternative medicine is actively performed as a cancer therapy supplementary for food containing superfine dispersed LEN (beta-1, 3-glucan) in patients with unresectable or recurrent hepatocellular carcinoma in a multi-center study. In a 36 patient survival times of Lentinan-high-binding group were significantly longer than those of Lentinan-low-binding group. LEN is effective for hepatocellular carcinoma patients' survival especially when long-time ingestion is implemented. Assessment of Lentinan-binding CD14+ monocytes is a promising prognostic predictor [179]. Glucans have a long history as nonspecific biological modulators and are involved in the effects of three different glucans on immune reactions such as the synthesis and release of interleukin (IL)-1, IL-2, IL-4, IL-6, IL-8, IL-13, and tumor necrosis factor-alpha. In addition, a LEN derivative inhibited growth of tumorcells in vivo and affected expression of several important genes in breast cancer cells $[143,144]$. LEN CD8-positive cells appeared to have suppressed tumor cell proliferation. CD4- positive cells appeared to be involved in this activity of CD8-positive cells [180]. LEN has a life prolonging effect in non-operable, recurrent gastric cancer patients in combination with chemotherapy [181]. 
Dendritic cells DCs might play an important role in chemotherapy, and LEN presents a promising chemo immunotherapy, which might lead to better survival for cancer patients [182]. Yoshino, et al. demonstrated that patients with advanced cancer may have impaired cellmediated immunity caused by an imbalance between Th1 and Th2 responses [183]. LEN can cancel Th2-dominant condition in patients with digestive cancers and may improve the balance between Th1 and Th2 [183]. LEN may augment the effects of erythropoietin (Epo) on erythropoiesisin the course of anemia and the decreased erythropoiesis in cancer patients receiving chemotherapy [184]. Multiple biological therapies are considered to be potentially effective against the highly malignant advanced tumors [185].

\subsection{Mistletoe}

NKC play an important role in cell-mediated immune responses against tumor cells [186]. Strengthening the immune system might help to control or even to eradicate malignant tumors. Insights into the mechanisms of hostdefense against cancer cells and the modification of immune-effector cells might pave the way to efficient treatment strategies, even in the preventive application setting [187].

As reviewed by Braedel-Ruff in 2010, extracts produced from Viscum album L. (mistletoe), theyare widely used in complementary medicine for the treatment of cancer [186]. In many preclinical and clinical studies, viscumalbum extracts were shown to exert immunomodulatory functions. The NKC are involved in direct tumor cell destruction. There is evidence that they may contribute to the prevention of the control of metastases. Twenty three tumor patients were treated subcutaneously with increasing concentrations of aqueous mistletoe extracts. The relative amount of lymphocytes and the number of NKC increased significantly $[187,188]$. Non-selected tumor patients $(\mathrm{n}=12)$ with various solid carcinomas were treated continuously twice weekly over 48 weeks with the aqueous mistletoe extract with a statisticcally significant risein the cell count of total lymphocytes, monocytes and NKC [189]. The raised cell count of NKCs correlated with the significantly increased cytotoxic activity versus tumor cells. Other lymphatic subpopulations, for instance $\mathrm{CD} 3+, \mathrm{CD} 8+, \mathrm{CD} 3+\mathrm{CD} 4+$ and $\mathrm{CD} 3+\mathrm{CD} 8+$ cells, also revealed distinct rise in cell countin the course of treatment. Within 6 weeks after completion of treatment, the overall values dropped again. NKCs were still raised in comparison to the baseline values. These studies showed a significant improvement in the immune status of tumor patients, which has shown to be safe over a long period [189]. Breast cancer patients $(\mathrm{n}=20)$ received a single intravenous infusion of Iscador, a mistletoe (Viscum album L.) extract. NKC and anti- body-dependent cell-mediated cytotoxicity (ADCC) activities as well as the number of large granular lymphocytes (LGL) showed significant increases in NKC/ADCC activities and LGL frequencies were observed [190]. Cultures of human PBMC as well as cultures of preseparated peripheral non-adherent cells (PNAC) and monocytes showed enhancement of NKC cytotoxicity against K562 tumor cells [191]. The mistletoe lectins have been identified as the main active principle of mistletoe extracts. They have been shown to exhibit induction of cytokine secretion and increased activity of NKC [192]. Clinical application of mistletoe extracts or isolated lectins is reported to induce number and activity of NKCin peripheral blood in a dose-dependent manner [193]. Mistletoe lectins (MLs) is specific for galactose, high-density galactose expression in malignant melanoma is a predictor of poor prognosis [194].

\subsection{N-Acetyl-Cysteine}

$\mathrm{N}$-Acetyl-Cysteine (NAC) is a natural, in vivo derived antioxidantthat induces modulation of glutathione (GSH) cellular content effects. The levels of GSH are decreased significantly in NKCs derived from individuals with HIV infection [195]. Downregulation of class I by lactacystin (LAC) significantly enhances NKC-mediated lysis of multiple myeloma (MM). Furthermore, the downregulation degree of class I was associated with increased susceptibility of myeloma cells to NKC killing [66-68]. An important role for $\mathrm{NKC}$ in the regulation of $\mathrm{T}$-cell responses is emerging, although the receptor pairs regulating the NKC-T-cell interaction have still not been identified. Impaired poliovirus receptor (PVR) is reduced in the presence of the reactive oxygen species (ROS) scavenger NAC. NKCs lyses allogeneic responses were efficient with NAC [196]. Gamaleî studied NAC ability to change the phenotype properties of several transformed and embryonic cells [197]. It demonstrated that treatment with NAC $(10 \mathrm{mM})$ results in a loss of susceptibility to NKC activity. Murine embryonic fibroblasts (MEFs) pretreated with $10 \mathrm{mM} \mathrm{NAC}$ as well as transformed cells lose their susceptibility to NKC activity. The loss of cell sensitivity to NKC cytolytic activity was accompanied by a reorganization of the actin cytoskeleton and the appearance of well-pronounced stress.

Alpha-lipoic acid (ALA) and NAC showed an increase sensitivity of 3T3-SV40 fibroblasts to lytic activity of NKC. ALA reduced significantly the fibroblast sensitiveity in several hours, whereas NAC $(10 \mathrm{mM})$ did not change it. Both NAC and ALA pathway includes inactivation of matrix metalloproteinase (MMP-2) [25]. NAC is a known antioxidant and induces modulation of glutathione cellular content effects. Usage in stem cell transplantation (SCT) may be relatively safe with regard to the graft-vs.-leukemia effect (GVL) effect, yet further 
clinical studies are warranted [198]. 18 - $20 \mathrm{~h}$ cultivation of transformed mouse fibroblasts 3T3-SV40 in the presence of antioxidant, NAC (NAC, $10 \mathrm{mM}$ ), did not change their sensitivity to lysis by NKC mouse splenocytes. However, in 18 - $20 \mathrm{~h}$ after NAC removal 3T3-SV40 cells demonstrated resistance to NKC activity. This effect may be due to the NAC-induced modifications of the cell surface and extracellular matrix proteins [199]. Antioxidants are able to protect umbilical blood mononuclear cells against oxygen stress and affect oxygen stress mediated immune function inhibition of umbilical blood [200].

With aging there is an increase of oxidative stress due to an imbalance between the oxidant production and the antioxidant levels in favor of the former. Since immune cell functions are specially linked to ROS generation, the oxidant/antioxidant balance is essential for these cells. The ingestion of a diet supplemented with two thiolic anti-oxidants, such as NAC and thioproline (TP) has been shown to be beneficial to the immune response in prematurely aging mice (PAM) [201]. The ingestion of very high amounts $(0.3 \%)$ of thiols by aged animals increasedthe phagocytosis, the NKC activity and especially the lymphoproliferative response to the mitogen, a function that is very depressed with aging. With aging there is an increase of oxidative stress due to an imbalance between the oxidant production and the antioxidant levels in favor of the former. Since immune cell functions are specially linked to ROS generation, the oxidant/antioxidant balance is essential for these cells. The ingestion of thiols by aged animals increased the phagocytosis, the NKC activity and specially the lymphoproliferative response to the mitogen, a function that is very depressed with aging [202]. These results add new insights to the key role played by redox imbalance as a modulator of immune system homeostasis and suggest that an antioxidant drug such as NAC could be useful against pathologies associated with an increase in lipid peroxidation [203].

The induction of endogenous glutathione in living cells immediately after low-dose gamma irradiation is at least partially responsible for the appearance of enhanced NKC activity [204]. Interleukin-12 (IL-12) is secreted from monocytes and macrophages; it exerts pleiotropic effects on $\mathrm{T}$ cells and $\mathrm{NKC}$, and stimulates IFN-gamma secretion. IFN-gamma and IL-4 oppositely affect the glutathione $(\mathrm{GSH}) /(\mathrm{GSSG})$ glutathione balance, which may regulate IL-12 secretion from AM in response to LPS [205].

Massive loss of sulfur in HIV-infected subjects and the present demonstration of the immunoreconstituting effect of cysteine supplementation indicate that the HIV-induced cysteine depletion is a novel mechanism by which a virus destroys the immune defense of the host and es- capes immune elimination [206]. Two randomized placebo-controlled trials have shown that treatment of HIV-infected patients with NAC caused in both cases a significant increase in all immunological functions under test, including an almost complete restoration of $\mathrm{NKC}$ activity [207]. This stimulation of the NKC activity by antioxidants is an important favorable response, especially in old mice, in which age results in a decrease in NKC function and, therefore, in a higher incidence of neoplasia [208]. Suppression of calcineurin and NFAT activation is a mechanism by which oxidative stress inhibits FasL induction in activated NKCs. Thiol-reducing compounds, such as NAC, are required for maintenance of optimal NKC functions under physiologic oxidative conditions [209]. NAC raises GSH levels and increases cytotoxicity. Hepatic GSH is important to the optimal functioning of the hepatic immunity that protects against hepatoma development [210].

Control of cell cycle progression in human NKC through redox regulation of expression and phosphorylation of retinoblastoma gene product protein using NAC [211]. Fas-sensitive cells were incubated with NAC, intracellular GSH was increased and Fas-mediated apoptosis was blocked. Mediated apoptosis, but not perforin-dependent killing, is modulated by intracellular intracellular glutathione (GSH) in human T lymphocytes [212].

NAC is capable of enhancing the adhesion properties of the epithelial cell line. NAC could thus behave as a drug influencing certain cytoskeleton-dependent cell processes in a non-histotype dependent manner. Importance of intracellular oxidative balance on cell-mediated cytotoxicity was performed by analyzing the effects of the NAC, on NKC-mediated cytotoxicity. The results obtained indicate that an enhancement of target cell (TC) killing can be detected when a pre-exposure of effector cells (EC) to NAC was performed [213]. NAC may be useful as an adjunct to increase the antitumor activity of IL-2/LAK therapy [214]. Anti-tumor effect of haemin and IL-2 was enhanced ( $63 \%$ decrease in metastases) by administration of NAC. Since haemin can safely be administered to patients, it may represent a new class of biologic response modifiers that could enhance IL-2-mediated anti-tumor effects [215].

NAC has ability to change the phenotype properties of several transformed and embryonic cells. The loss of cell sensitivity to NKC cytolytic activity was accompanied by a reorganization of the actin cytoskeleton [197]. The results obtained demonstrated that the direct effect of NAC (having reduced thiol groups), and the indirect one, ALA (reducing thiol groups and acting as a direct antioxidant only inside the cell) activate principally different intracellular signal pathways. However, both NAC and ALA pathway includes inactivation of MMP-2 resulting in a strong synergistic antiangiogenic activity [25]. NAC mi- 
ldly inhibits the graft-vs.-leukemia effect but not the LAK activity [198]. Intracellular oxidative balance on cell-mediated cytotoxicity was performed by analyzing the effects of NAC. NAC as a cytoskeleton thiolmodifier contributed to the activation of effector cells [213].

\subsection{Resveratrol}

For almost 200 years, scientists have suspected that wine consumption had something to do with "The French Paradox"- the fact that $50 \%$ more Frenchmen live to 100 than America and other countries, despite a rich, high fat diet. But only in recent years has the explanation become clearer. The polyphenols, such as Resveratrol (RES) found in red wine may slow down the aging process and help prevent age-related diseases including heart disease, cancer, alzheimers, diabetes, and others [216231]. RES and Vitamin C combination [216] is a strong activator of phagocytosis and antibody formation. Two different models of cancer treatment demonstrated that the combination strongly suppressed the growth of breast and lung tumors, most likely due to the stimulation of apoptosis.

RES can block cell proliferation and induce growth arrest and/or cell death in several types of cancer cells. The effect of RES on the induction of apoptosis via autophagy is mediated through ROS in human colon cancer cells [217], such as the combination of dietary supplements such as RES, Lycopene, Vitamin C and Anthocyanins. RES also reduced skin toxicity due to external beam radiotherapy in patients affected by breast cancer [218]. Interactions between various dietary cancer chemopreventive phytochemicals in drug transporter functions are not well studied, for example the effects of genistein and RES on the multidrug resistance protein 2 (MRP2) expressions. It can potentially interfere with each other's regulatory function on the cancer chemoprevention-related genes through a competitive mechanism [219]. RES down-regulates protein $\mathrm{S}$ expression in HepG2 cells [220]. RES has a variety of activities involved in the immune system and in longevity [221]. There are number of anticancer mechanism for resveratrol including modulation of the immune system through chemo preventative means. It can even function as a prooxidant against cancer cells as a dietary chemo preventative agent, thus earning the title as a so called longevity drug [222-224].

The cytotoxic effect has been shown to destroy a number of organ based cancers including colon cancer [217], pancreatic cancer [225], ovarian cancer [226], gastric cancer [83] and glioma cells [227]. It even diminishes the effects of cis platinum cytotoxicity [228]. In vivo cytotoxic activity of the natural killer (NK) cells isolated from resveratrol-pretreated rats is enhanced compared with that of the non-pretreated rats. Resvera- trol may act, like the IL-2 pathway, to enhance per- forin expression and cytotoxic activity [229]. RESmodu- lates several human immune cell functions and suggest that this activity may be related to its effects on cytokine production by both CD4+ and CD8+ T cells [230]. The mechanisms RES is usedto destroy cancer cells include increment in NKC activity [231] NKC by direct cytotoxicity and induced apoptosis in target cells using the perforin and granulozyme activity.

\subsection{Selenium}

Selenium (Se) has been recognized for years as an essential trace element for animals (National Research Council, 1980). It is generally accepted that Se is necessary for optimum performance of the immune system. Selenium deficiency results in immune suppression but little is known concerning the effect of excess Se on immune function. Recent evidence suggests that oral $\mathrm{Se}$ supplementation may impede oncogenesis. Antioxidant supplementation with Se may be useful for the preservation of health and functional longevity in aging populations [232]. Enhancement of NKC activity may be an underlying mechanism of the anti-carcinogenic properties of Se. Thus, neoplasms that are NKC sensitive could be prevented and/or responsive to Se therapy [233]. Enqvist et al. in 2011 showed that selenite may be used to potentiate the anti-tumor cytotoxicity in settings of NKC-based immunotherapies [234]. Hawkes et al. in 2009 administered 42 men $300 \mu \mathrm{g}$ of Se [235]. Supplementation increased blood Se concentration by $50 \%$ and increased counts of NKC and T lymphocytes expressing both subunits of the high affinity interleukin-2 receptor (IL2R). Selenium supplementation can protect mice against the toxicity of iodine [236]. Selenium, betacarotene, and glutamine can also increase the number and/or cytotoxic activity of NKCs [237]. The antioxidant supplementation may be useful for the preservation of health and functional longevity in aging populations [232].

\subsection{Vitamin B Complex}

Vitamin B (Vit B) is a compilation of eight different vitamins, known as Vitamin B complex, found naturally in high-protein foods, such as fish, and leafy greens. Vitamin supplementation is associated with increased antibody titer response to both hepatitis B and tetanus vaccines as a result of macrophage and $\mathrm{T}$ cell stimulation. Because of these findings and others, nutraceuticals are becoming more widely accepted as an adjunct to conventional therapies for enhancing general well-being [238]. High blood concentrations of folic acid (Vitamin B9), however, may be related to decreased NKC cytotoxicity, and high folate status may reduce the response 
to antifolate drugs used against malaria, rheumatoid arthritis, psoriasis, and cancer [239]. According to Erkut et al., Vitamin B12 may have important immuno-modulatory effects on cellular immunity, and abnormalities in the immune system in pernicious anemia are restored by Vitamin B12 replacement therapy [240]. Vitamin B12 might play an important role in cellular immunity, especially relativing to $\mathrm{CD} 8+$ cells and the NKC system, which suggests effects on cytotoxic cells. Tamura et al. concluded that vit. B12 acts as an immunomodulator for cellular immunity. The molecular mechanism responsible for the age-dependent decline of NKC is restored [241].

It has been demonstrated that surgery may induce im-munosuppression. This finding could influence the clinical course of surgically treated cancer patients and vitamin supplementation is warranted. Moreover, preliminary experimental studies have shown that a preoperative injection of IL-2 response is well known. IL-2induced neutralization of postoperative lymphocytopenia is associated with a prolonged survival time in advanced colorectal cancer patients [242]. Patients given 5-fluorouracil (5-FU)/IFN-alpha show augmentation of NKC function and abrogation of 5-FU-induced suppression of LAK cell activity [243]. While Vitamin B6 status is not a primary etiological factor in HIV-1-related immunological dysregulation, it appears to be an important cofactor of immune function [244]. It appears that Vitamin B6 is an essential nutrient for maintenance of normal T-cell function in vivo [245].

\subsection{Vitamin C}

Preserved function of the immune system is an excellent marker of health and longevity. Micronutrients such as Zinc, Selenium, iron, copper, beta-carotene, Vitamins A, C, and $\mathrm{E}$, and folic acid can influence several components of innate immunity. Deficiencies in zinc and Vitamins A and D may reduce NKC function, whereas supplemental zinc or Vitamin C (Vit C) may enhancetheir activity [246]. The improvement of leukocyte functions after ingestion of Vit $\mathrm{C}$ suggests that this antioxidant supplementation may be useful for the preservation of health and functional longevity in aging populations [232]. In one study, the in vitro effects of $\mathrm{Vit} \mathrm{C}$ and selenium on NKC activity of ss-thalassemia major patients were investigated and found that Vit $\mathrm{C}$ enhanced NKC activitysignificantly [247]. As antioxidant diet supplementation decreases oxidative stress, it may be useful to treat hypertension and increase longevity in agreement with the oxidation/ inflammation theory of aging [248]. Combinations of 1 $\mathrm{mM}$ for thioproline and NAC and $5 \mu \mathrm{M}$ for Vit $\mathrm{C}$ and Vitamin $\mathrm{E}$ induced enhancement of the NKC activity at all ages studied. This stimulation of the NKC activity by antioxidantsis an important favorable response, especially in old mice, in which age results in a decrease in
NKC function and, therefore, in a higher incidence of neoplasia [208]. After exposure to many toxic chemicals, $\mathrm{NKC}$ function can be decreased significantly. Immune functional abnormalities can be restored after toxic chemical exposure by oral usage of Vitamin C [249]. No convincing data exist that moderate exercise training is linked to improve $\mathrm{T}$ helper cell counts in patients with HIV, or enhance immunity in elderly participants [250]. The plasma level of interleukin (IL)-6 and IL-1 receptor antagonist increased 20- and 3-fold after exercise. The plasma level of creatine kinase was increased sixfold the day after exercise. The concentrations of CD4+ memory $\mathrm{T}$ cells, CD8+ memory and naïve $\mathrm{T}$ cells, and NKC increased at the end of exercise [251]. These effects may be related to the increase Nutraceuticals taken by active individuals, which include vitamins. Natural products such as Vit C may increasecytotoxic activity of NKC. Tumor Necrosis Factor alpha (TNF-alpha) decreases DNA damage in patients with late-stage cancer. A combination of Nutraceuticals can raise NKC function and TNF-alpha activity and result in improved clinical outcomes in patients with late stage cancer. In a study of 20 patients with stage IV, end-stage cancers were given vitamin C. As of a mean of 6 months, 16/20 patients were still alive. The 16 survivors had significantly higher NKC function than baseline ( $p<0.01$ for each) [252]. Vit $\mathrm{C}$ has been found to enhance NKC activity and antibody dependent cellular cytotoxicity (ADCC). This increased survival was completely abrogated when NKC and killer (K) cell activities were depleted by cyclophosphamide [253]. Platelets aggregation around migrating tumor cells offers protection against the cytotoxic activity of the NKCs. Ascorbic acid inhibited platelet aggregation increased the NKC cytotoxicity $285 \%$. The results suggest the role of ascorbic acid in increasing the susceptibility of tumor cells to NKC; the Vit C could be used as part of a multidrug therapy to treat diseases which up to now have been treated only through chemotherapy [254]. A study was reported to examine the effect of 500 to 5000 $\mathrm{mg}$ of Vit $\mathrm{C}$ on DNA adducts on NKC activity [255]. At doses greater than $500 \mathrm{mg}$, this cellular absorption was not increased further, and all doses produced equivalent increases in ascorbic acid on days 1 to 15. After a period of 1 week, with no placebo or vitamin washout, Vit C levels along with functional assays returned to the baseline and became equivalent to placebos. These studies concluded that Vit $\mathrm{C}$ was an antioxidantand that doses up to $5000 \mathrm{mg}$ did not induce mutagenic lesions nor had negative effects on NKC activity, apoptosis, or the cell cycle. VitC concentrations in the plasma and leukocytes rapidly decline during infections and stress. Supplementation of Vit Cwas found to improve components of the human immune system such as antimicrobial and NKC activities. Zinc deficiency was been shown to also impair 
cellular mediators of innate immunity such as phagocytosis, NKC activity, and the generation of oxidative burst. Therefore, both nutrients play important roles in immune function and the modulation of host resistance to infectious agents. A large number of randomized controlled intervention trials with intakes of up to $1 \mathrm{~g}$ of Vitamin C and up to $30 \mathrm{mg}$ of zinc are available. These trials document that adequate intakes of Vitamin $\mathrm{C}$ and zinc ameliorate symptoms and shorten the duration of respiratory tract infections including the common cold [256].

\subsection{Vitamin D3}

A novel inflammatory crosstalk between NKCs and eo-sinophils via IL-15/IL-8 axis can be modulated by Vitamin D3 [257]. Vitamin D3 increases the susceptibility of cancer cells to NKCs and may therefore have a preventive role in melanoma occurrence or potentiate the anticancer effects of NKC-cell immune therapy [74]. The Vitamin D3 up regulated protein 1 (VDUP1) and is a stress-response gene that is up regulated by 1,25-dihydroxyvitamin $\mathrm{D} 3(1,25(\mathrm{OH}) 2 \mathrm{D} 3)$ in tumor cells. Lee et al. suggested that VDUP1 is a critical factor for the development and function of NKCs in vivo [258]. Low vitamin D status is associated with an increased risk of immune-mediated diseases like inflammatory bowel disease (IBD) in humans [259]. Acute myeloid leukemia (AML) displays low levels of ligands for the activating immunoreceptor NKCG2D and will evade NKC immunosurveillance. These findings identify NKCG2D ligands are thus targets of leukemia differentiation therapy and suggest a clinical benefit in combining a pharmacological approach with NKC-based immunotherapy in AML [260]. Several lines of evidence suggest that 1,25-dihydroxyvitamin D3 $(1,25 \mathrm{D} 3)$ may be important in chemoprevention of human cancer. Human promyelocytic leukemia cells HL60 cultured in the presence of $30 \mathrm{nM} 1,25$ D3 for three years exhibited a reduced rate of tumor growth when injected into $\mathrm{nu} / \mathrm{nu}$ mice. These results suggest a mechanism for the reported chemopreventive effects of sunlight-generated 1,25 D3 or dietary Vitamin D3 [261]. Given the importance of proper invariant NKCT (iNKCT) cell function in health and disease, this prenatal requirement for Vitamin D suggests that in humans, the amount of Vitamin D available in the environment during prenatal development may dictate the number of iNKCT cells and potential risk of autoimmunity [262].

\subsection{Vitamin $E$}

Cancer patients with advanced disease display signs of immune suppression, which constitute a major obstacle for effective immunotherapy. Both T cells and NKCs are affected by a multitude of mechanisms of which the generation of reactive oxygen species is of major importance.
DCs based vaccines have only exhibited minimal effecttiveness against established tumors in mice and humans. Tocotrienol-rich fraction (TRF) has the potential to be an adjuvant to augment DC based immunotherapy [263]. Two weeks of high-dose treatment with the anti-oxidant Vitamin E enhanced NKC function in cancer patients by protecting from oxidative stress and in patients with colorectal cancer [264]. The improvement of leukocyte functions after ingestion of thiolic antioxidants suggests that antioxidant supplementation may be useful for the preservation of health and functional longevity in aging populations. Immune response is impaired in the elderly but NKC activity increased in supplemented subjects and decreased in nonsupplemented individuals [232]. Interleukin-2 production by PBMC and the proportion of $\mathrm{T}$ cells with NKC activity decreased in controls and did not change in supplemented subjects. Supplemented subjects reported less infection than no supplemented individuals (in $13 \%$ and $22 \%$ of scheduled visits, respectively; $p=$ 0.02). Supplements included nutrients in parts, $480 \mathrm{kcal}$, 31 g proteins, 120 IU Vitamin E, 3.8 ug Vitamin B12, 400 ug folic acid [265]. The powerful influence of host nutriational status on the course of viral infection has been shown [266]. The role of alpha-vitamin E and Se on human lymphocyte oxidative stress and T-cells proliferation indicated that alpha-vitamin $\mathrm{E}$ and Se have interacttive effects as oxygen radical scavengers, thus promoting human lymphocyte response to antigens [267]. Twenty male recreational runners randomly received either antioxidants $(500 \mathrm{mg}$ of Vitamin $\mathrm{C}$ and $400 \mathrm{mg}$ of vitamin E) or placebo for 14 days before and 7 days after a $5 \%$ downhill 90 -min treadmill run at $75 \% \mathrm{VO}_{2 \max }$. The plasma level of interleukin (IL)-6 and IL-1 receptor antagonist increased 20- and 3-fold after exercise. In the supplemented group, plasma level of creatine kinase was increased sixfold the day after exercise. The concentrations of CD4+ memory T cells, CD8+ memory and naïve $\mathrm{T}$ cells, and NKC increased at the end of exercise. On the other hand exercise in a person who is unconditioned or unaccustomed to exercise will induce oxidative damage and resulted in muscle injury [268].

\subsection{Zinc}

Zinc $(\mathrm{Zn})$ is one of the most important trace elements in the body and it is essential as a catalytic, structural and regulatory ion. It is involved in homeostasis, in immune responses, in oxidative stress, in apoptosis and in aging. Deficiency of zinc is prevalent worldwide in developing countries and may affect nearly 2 billion subjects. The major manifestations of zinc deficiency include growth retardation, hypogonadism in males, cell-mediated immune dysfunctions, and cognitive impairment. Zinc not only improves cell mediated immune functions but also functions as an antioxidant and anti-inflammatory agent. 
Prasad et al. recommended further studies and propose that zinc should be utilized in the management and chemoprevention of cancer [269].

Zinc-binding proteins (metallothioneins, MTs), are protective in situations of stress and in situations of exposure to toxic metals, infections and low Zn nutrition. MTs play a key role in $\mathrm{Zn}$-related cell homeostasis due to their high affinity for $\mathrm{Zn}$, which is in turn relevant against oxidative stress and immune responses, including NKC activity and aging, since NKC activity and $\mathrm{Zn}$ ion bioavailability decrease in aging. Physiological supplementation of $\mathrm{Zn}$ in aging and in age-related degenerative diseases corrects immune defects, reduces infection relapse and prevents aging. Zinc is not stored in the body and excess intakes result in reduced absorption and increased excretion. Nevertheless, there are cases of acute and chronic $\mathrm{Zn}$ poisoning [270]. Aging is accompanied by chronic in-flammation and oxidative stress, which lead to a marked impairment of immune function and therefore increased mortality. Data suggest that improvement of leukocyte function and restoration of redox balance after consumption of adequate levels of antioxidants from adulthood may be useful to attain healthy aging [271].

The promyelocytic leukemia zinc-finger (PLZF) is essential for the development of innate $\mathrm{T}$ cells(as represented by $\mathrm{NKC} \mathrm{T}$ cells) for acquisition of their unique innate immune properties [272]. The transcriptional regulator PLZF is highly expressed during the differentiation of NKC T (NKCT) cells and is essential for the acquisition of their effector/memory innate-like phe-notype [273]. The Senescence-Accelerated Mouse (SAM) represents a group of inbred mouse strains developed as a model for the study of human aging and age-related diseases [274]. Schnurri (Shn)-2 is a large zinc finger-containing protein implicated in cell growth, signal transduction and lymphocyte development. In Shn-2(-/-) mice, Yamashita et al. observed decreased cytotoxicity of NKC accompanied by decreased expression of perforin and granzyme-B [275]. Thus, Shn-2 is considered to play an important role in the activation and function of NKCs and the development of $\mathrm{T}$ cell lymphoma in vivo. Most liver NKCT cells failed to recirculate. Antibody blocking experiments established that they were retained locally through constitutive LFA-1-interce- llular adhesion mole-cule (ICAM) 1 interactions. This unprecedented lifelong intravascular residence could be induced in conventional CD4 $\mathrm{T}$ cells by the sole expression of PLZF, a transcription factor specifically expressed in the NKCT lineage [276]. The nutritional factor, zinc, may remodel these changes with subsequent healthy aging, because zinc improves the inflammatory/immune response as shown by in vitro and in vivo studies. Zinc supplementation in old C-carriers restores NKC cytotoxicity and zinc status. The genetic variations of the IL-6- loci are useful tools for the choice of old people for zinc supplementation [277].

Interferons (IFNs) direct innate and acquired immune responses and, accordingly, are used therapeutically to treat a number of diseases. The promyelocytic leukemia zinc finger (PLZF) protein is part of the IFN response [278]. During aging, dysregulated immune functions occur contributing to increased susceptibility to morbidity and mortality. NKC and NKC T (NKCT) cell cytotoxicity, representing one of the bestmodels of innate immune response, decreases in aging as well as IFNgamma pro-duction by both activated types of cells. The role played by zinc and MT is crucial because some MT polymorphisms are involved in maintaining innate immune response and intracellular zinc ion availability in aging with thus a role of MT genetic background to escape some age-related diseases with subsequent healthy aging and longevity [279].

Muzzioli et al. evaluated the effect of zinc on the kinetic of development of CD34(+) stemcell progenitors towards NKCs in young and old ages [280]. CD34(+) cells was greatly lower in old than in young subjects. These cells progressively decreased in cultures from young subjects whereas they remained at very low levels in old donors. Zinc influences the proliferation and differentiation of $\mathrm{CD} 34(+)$ progenitors both in young and old ages.

Down syndrome is associated with an increased susceptibility to infections due to a deficiency of both specific and nonspecific immunity. Plasma level of zinc is normal from birth until 5 years but with a temporal trend of progressive reduction. This observation supports the hypothesis that a pharmacological supplementation may be necessary in Down syndrome children only after 5 years of age [281]. Proinflammatory cytokine response and NKC activity are controlled by the availability of zinc ions, whose intracellular transport is regulated by angiogeneic metallothioneins. IL-6, MCP-1 and NKC activities were evidenced following supplementation, indicating the genetic background as one of the determinants for identifying groups of subjects that can take advantage of therapeutic intervention [282]. These results demonstrated an enhanced production of IL-12 during the acute phase of infection in zinc-supplied groups. So Brazão et al. concluded that zinc supplementation leads to an effective host's immune responseby up-modulating the host's immune response, thus contributing tothe reduction of blood parasites [283]. Prasad et al. concluded that zinc has an important role in cell-mediated immune functions and also functions as anti-inflammatory and antioxidant agent [269].

The NKC maturation from CD34(+) hematopoietic cell precursors is a complex process that requires the synergistic effect of different cytokines and growth fac- 
tors. Although there have been a number of important advances in the understanding of the NKC differentiation, the developmental step leading to mature NKC is still poorly defined. Zinc influences the proliferation and differentiation of CD34(+) progenitors [280]. Nutritional intake of $10 \mathrm{mg}$ of zinc increases the quantity of interferon-gamma-producing NKC and strengthensthe immune system against neoplasms and viral infections [284]. It is very important to include assays of NKC markers and functions in future longitudinal studies in order to investigate this point in detail as well as to consider the trace element zinc as an essential cofactor for optimal NKC activity [285]. Vitamin C concentrations in the plasma and leukocytes rapidly decline during infections and stress. Supplementation of Vitamin C was found to improve components of the human immune system such as antimicrobial and NKC activities, lymphocyte proliferation. Vitamin $\mathrm{C}$ and zinc reduce the incidence and improve the outcome of pneumonia, malaria, and diarrhea infections, especially in children in developing countries [256]. Zinc prevents immune deficiencies in cellmediated immunity in healthy $55-70$ years old [286].

\section{Summary}

Table 1 is a summary of the mechanisms and disease targets published in the literature for the supplements described herein. In Table 1, Direct Anti-cancer Activity was shown by garlic, Lentinan, Resveratrol, Selenium, Vitamins C, D3, E and Zinc. Increased NKC activity was shown by all but ALA and Vitamin B complex, which revealed mixed reviews in the literature. ALA and Vitamin B complexmainly acts as an anti-inflammatory and BRM. When supplements are used in cancer patients, those with both NKC stimulatory and direct cytotoxicity functions would contribute to the demise of the cancer cells. Therefore, the mechanisms of killing, including the BRM, antiangiogenic, antioxidant and anti-inflammatory activities, would be difficult to determine in cancer paients. Determination of the actual NKC role is com-

Table 1. Summary of mechanisms and disease targets for the components.

\begin{tabular}{|c|c|c|c|c|}
\hline Component & NKC Activity & Anti-cancer & Mech. Action & Disease(s) \\
\hline $\mathrm{ALA}^{1}$ & \pm & & Anti-inflammatory & $\begin{array}{l}\text { Diabetes, MS } \\
\text { Alzheimer's }\end{array}$ \\
\hline Arabinoxylan & + & & $\mathrm{BRM}^{2}, \mathrm{Apop}^{3}$ & $\begin{array}{c}\text { Cancer } \\
\text { Respiratory }\end{array}$ \\
\hline Curcumin & + & & $\begin{array}{c}\text { Chemoprev }^{4} \text {, Antiox } \\
\text { Antibacterial, Apop }\end{array}$ & Cancer \\
\hline Garlic & + & + & Antiox, Apop & Cancer \\
\hline Geinstein & + & & Antiag $^{6}$ & Cancer \\
\hline Ginseng & + & & & Cancer,MS \\
\hline Lentinan & + & + & Erythropoiesis & $\begin{array}{c}\text { Cancer } \\
\text { Anemia, Heart }\end{array}$ \\
\hline Mistletoe & + & & & AIDS, Cancer \\
\hline NAC & + & & Apop, Antiag & AIDS, Cancer \\
\hline Resveratrol & + & + & BRM, Apop & $\begin{array}{c}\text { Cancer, MDR } \\
\text { Longevity }\end{array}$ \\
\hline Selenium & + & + & BRM & $\begin{array}{l}\text { Cancer, } \\
\text { Longevity }\end{array}$ \\
\hline Vitamin B & \pm & & BRM & $\begin{array}{c}\text { Arthritis, } \\
\text { Energy, Malaria }\end{array}$ \\
\hline Vitamin $\mathrm{C}$ & + & + & Antiox & $\begin{array}{c}\text { Longevity } \\
\text { Cancer, HIV } \\
\text { Exercise }\end{array}$ \\
\hline Vitamin D3 & + & + & $\begin{array}{l}\text { Anti-inflammatory } \\
\text { BRM }\end{array}$ & Stress, chemo-prevention \\
\hline Vitamin E & + & + & $\mathrm{DC}^{7}$, Antiox & Autoimmunity \\
\hline Zinc & + & + & $\begin{array}{c}\text { Anti-inflammatory } \\
\text { Antiox }\end{array}$ & $\begin{array}{c}\text { Cancer, } \\
\text { Antiaging, } \\
\text { Stem Cells } \\
\text { Down } \\
\text { Syndrome }\end{array}$ \\
\hline
\end{tabular}

${ }^{1}$ Alpha Lipoic Acid; ${ }^{2}$ Biological Response Modifier; ${ }^{3}$ Apoptosis; ${ }^{4}$ Chemoprevention; ${ }^{5}$ Antioxidant; ${ }^{6}$ Anti-angiogenesis; ${ }^{7}$ Dendritic Cells. 
tpounded by some of the supplements being directly cytotoxic to cancer cells (a good thing).

To add another level of complexity to this determination, Table 2 reveals examples from the literature that shows synergism between components that affect the viability of cancer cells. A true measure of the NKC effect is complicated by synergistic and possibly even antagonist effects.

Regardless, the NKC is pivotal in the body's process of recognizing and destroying cancer cells. The development of a combination of supplements in the proper combinations into a tablet or capsule form would be an important part of the prevention and treatment of cancer that complements the classical approaches. The very act of taking supplements with the education and encouragement of one's physician would go a long way in thehealth of the patient. Besides, physicians can encourage health and wellness to promote good mental health in their patients (and themselves), which leads to healthy life style changes, including eating the right foods, exercise, and adequate sleep with mental and spiritual well-being. The physician can greatly influence decreasing depression that follows a cancer diagnosis with a positive attitude that "one is doing something" and has the endorsement of the physician and family.

There is some evidence that cancer is a malfunction of the immune system, and the $\mathrm{NKC}$ is pivotal in preventing cancer from developing on a cellular level. To protect against cancer and treat it, a variety of treatments are necessary. In the same vein the prevention and treatment of cancer using supplements relies on a multifaceted approach. Therefore multiple components are necessary. The Formulation (theformulation.com) contains 13 necessary components. While it is next to impossible to receive approval for multiple components (certainly very expensive), the Formulation addition of a "NKC tablet" will require advertising restricted to health and wellness, while advocating "not to be used for the diagnosis and treatment of any diseases". The physicians along with the public will have to educate themselves from publications and the internet as to the value of the supplements. This educational process must be driven by the masses, since

Table 2. Examples of literature references showing synergism between components.

\begin{tabular}{cc}
\hline Arabinoxylan—Curcumin & {$[30]$} \\
\hline Resveratrol—Vitamin C & {$[216]$} \\
NAC-Vitamin C & {$[287]$} \\
Vitamin C-Zinc & {$[256]$} \\
Vitamin E, B12 Folic acid & {$[265]$} \\
Vitamin E-Selenium & {$[267]$} \\
\hline
\end{tabular}

companies are restricted by the Food and Drug Administration. In fact, the medical and pharmacy schools need courses on natural medicines. Since over $40 \%$ of cancer patients are taking supplements, and over $70 \%$ of the older public is taking some form of supplementation, the medical community has a duty to educate future physiccians in the value of supplementation. Certainly, the scientific literature and the great interest in clinical trials reveal this importance. The FDA could go a long way in allowing this education process to take place by allowing the citation of well documented scientific studies by companies selling natural products, especially those showing scientific proof of NKC stimulation in the prevention and treatment of cancer.

\section{Acknowledgements}

We thank our students, Hannah Rose, Weston Keen, Charlie Overturf, Mark Allen, Seth Blackwell and Patrick Kent for their assistance in researching for this manuscript. We thank Tony Kirk, Bonita Thornthwaite and Edra Shalla for their untiring rewriting of this manuscript. Special thanks to Kyle Thornthwaite for his animations. We thank everyone who has encouraged me for the past 40 years in the Natural Killer cell research, especially Bonita, my wife of 43 years. Special thanks to Dr. Robert Leif, my mentor, who allowed me to develop my own discoveries. Ithank Marilyn Cayer for her expertise in Transmission Electron Microscopy. I thank my friend, Bill Peeples, for our nutraceutical collaborations for the past ten years. We thank the J. Immunology for the modified reproduction of Figures 1 and 2.

\section{REFERENCES}

[1] U. Winkler, et al., "Characterization, Application and Potential Uses of Biotin-Tagged Inhibitors for Lymphocyte Serine Proteases (Granzymes)," Molecular Immunology, Vol. 33, No. 7-8, 1996, pp. 615-623. doi:10.1016/0161-5890(96)00025-9

[2] S. L. Woodard, et al., "Chymase-Directed Serine Protease Inhibitor that Reacts with a Single 30-kD: A Granzyme and Blocks NK-Mediated Cytotoxicity," The Journal of Immunology, Vol. 153, No. 11, 1994, pp. 5016-5025.

[3] K. Thornthwaite, "Immune System-Natural Killer Cell," 2009.

http://www.youtube.com/watch?v=HNP1EAYLhOs

[4] J. T. Thornthwaite and R. C. Leif, "Characterization of Immune Cells Using the Plaque Cytogram Assay," Reticulendothelial Society, 1972.

[5] J. T. Thornthwaite and R. C. Leif, "The Plaque Cytogram Assay. I. Light and Scanning Electron Microscopy of Immunocompetent Cells," The Journal of Immunology, Vol. 113, No. 6, 1974, pp. 1897-1908.

[6] J. T. Thornthwaite, "The Buoyant Density Distribution and Plaque Cytogram Assay for Immunocompetent Cells," 
Master's Thesis, Florida State University, Tallahassee, 1974.

[7] J. T. Thornthwaite, et al., "A Technique for Combined Light and Scanning Microscopy of Cells, Scanning Electron Microscopy," Proceedings of the Workshop on Advances in Biomedical Applications of the SEM, IIT Research Institute, Chicago, 1976.

[8] J. T. Thornthwaite, et al., "A New Method for Preparing Cells for Critical Point Drying," Scanning Electron Microscopy, 1976, pp. 387-402.

[9] J. T. Thornthwaite and R. C. Leif, "The Plaque Cytogram Assay. II. Correlation between Morphology and Density of Linear Bovine Serum Albumin Buoyant Density Grardient-Separated Immunocompetent Cells," The Journal of Immunology, Vol. 114, No. 3, 1975. pp. 1023-1033.

[10] R. C. Leif, et al., "The Identification by Plaque Cytogram Assays and BSA Density Distribution of Immunocompetent Cells," Critical Factors in Cancer Immunology, 1975, pp. 103-158.

[11] J. T. Thornthwaite, "The Characterization of the Cells Involved in Cell-Mediated Immunity against Allogeneic and Syngeneic Tumor Cells," Ph.D. Thesis, Florida State University, Tallahassee, 1977.

[12] R. Kiessling, E. Klein and H. Wigzell, "Natural Killer Cells in the Mouse. I. Cytotoxic Cells with Specificity for Mouse Moloney Leukemia Cells. Specificity and Distribution According to Genotype," European Journal of Immunology, Vol. 5, No. 2, 1975, pp. 112-117. doi:10.1002/eji.1830050208

[13] R. Kiessling, et al., "Natural Killer Cells in the Mouse. II. Cytotoxic Cells with Specificity for Mouse Moloney Leukemia Cells. Characteristics of the Killer Cell," European Journal of Immunology, Vol. 5, No. 2, 1975, pp. 117-121. doi:10.1002/eji.1830050209

[14] R. B. Herberman and H. T. Holden, "Natural Cell-Mediated Immunity," Advances in Cancer Research, Vol. 27, 1978, pp. 305-377. doi:10.1016/S0065-230X(08)60936-7

[15] R. B. Herberman and H. T. Holden, "Natural Killer Cells as Antitumor Effector Cells," Journal of the National Cancer Institute, Vol. 62, No. 3, 1979, pp. 441-445.

[16] M. J. Robertson and J. Ritz, "Biology and Clinical Relevance of Human Natural Killer Cells," Blood, Vol. 76, No. 12, 1990, pp. 2421-2438.

[17] R. B. Herberman, M. E. Nunn and D. H. Lavrin, "Natural Cytotoxic Reactivity of Mouse Lymphoid Cells against Syn-Geneic Acid Allogeneic Tumors. I. Distribution of Reactivity and Specificity," International Journal of Cancer, Vol. 16, No. 2, 1975, pp. 216-229. doi:10.1002/ijc.2910160204

[18] R. B. Herberman and H. T. Holden, "Natural Cell-Mediated Immunity," Advances in Cancer Research, Vol. 27, 1978, pp. 305-377.

[19] R. B. Herberman and J. R. Ortaldo, "Natural Killer Cells: Their Roles in Defenses against Disease," Science, Vol. 214, No. 4516, 1981, pp. 24-30. doi:10.1126/science.7025208

[20] R. B. Herberman, "Cancer Immunotherapy with Natural Killer Cells," Seminars in Oncology, Vol. 29, No. 3, 2002, pp. 27-30. doi:10.1053/sonc.2002.33079

[21] R. Kiessling, J. C. Roder and P. P. Biberfeld, "Ultrastructural and Cytochemical Studies of Mouse Natural Killer (NK) Cells," Advances in Experimental Medicine and Biology, Vol. 121B, No. 3, 1979, pp. 155-163.

[22] S. Salinthone, et al., "Lipoic Acid Attenuates Inflammation via cAMP and Protein Kinase a Signaling," PLoS One, Vol. 5, No. 9, 2010, p. e13058. doi:10.1371/journal.pone.0013058

[23] S. Salinthone, et al., "Lipoic Acid Stimulates cAMP Production via the EP2 and EP4 Prostanoid Receptors and Inhibits IFN Gamma Synthesis and Cellular Cytotoxicity in NK Cells," Journal of Neuroimmunology, Vol. 199, No. 1-2, 2008, pp. 46-55. doi:10.1016/i.jneuroim.2008.05.003

[24] R. V. Schillace, et al., "Lipoic Acid Stimulates cAMP Production in T lymphocytes and NK Cells," Biochemical and Biophysical Research Communications, Vol. 354, No. 1, 2007, pp. 259-264. doi:10.1016/j.bbrc.2006.12.195

[25] N. A. Filatova, et al., "Effect of Alpha-Lipoic Acid on the Sensitivity of Transformed Fibroblasts to Lysis by Natural Killer Cells. Comparison with NAC Action," Tsitologiia, Vol. 51, No. 5, 2009, pp. 398-402.

[26] D. P. P. Belobrajdic, et al., "An Arabinoxylan-Rich Fraction from Wheat Enhances Caecal Fermentation and Protects Colonocyte DNA against Diet-Induced Damage in Pigs," British Journal of Nutrition, 2011, pp. 1-9.

[27] J. R. Pritchard, et al., "A Survey of Beta-Glucan and Arabi-Noxylan Content in Wheat," Journal of the Science of Food and Agriculture, Vol. 91, No. 7, 2011, pp. 1298-1303. doi:10.1002/jsfa.4316

[28] G. Muralikrishna and M. V. Rao, “Cereal Non-Cellulosic Polysaccharides: Structure and Function Relationship-An Overview," Critical Reviews in Food Science and Nutrition, Vol. 47, No. 6, 2007, pp. 599-610. doi:10.1080/10408390600919056

[29] M. Ghoneum and S. Agrawal, "Activation of Human Monocyte-Derived Dendritic Cells in Vitro by the Biological Response Modifier Arabinoxylan Rice Bran (MGN-3/ Biobran)," International Journal of Immunopathology and Pharmacology, Vol. 24, No. 4, 2011, pp. 941-948.

[30] M. Ghoneum and S. Gollapudi, "Synergistic Apoptotic Effect of Arabinoxylan Rice Bran (MGN-3/Biobran) and Curcumin (Turmeric) on Human Multiple Myeloma Cell Line U266 in Vitro," Neoplasma, Vol. 58, No. 2, 2011, pp. 118-123. doi:10.4149/neo_2011_02_118

[31] M. H. Bang, et al., "Arabinoxylan Rice Bran, (MGN-3) Enhances the Effects of Interventional Therapies for the Treatment of Hepatocellular Carcinoma: A Three-Year Randomized Clinical Trial," Anticancer Research, Vol. 30, No. 12, 2010, pp. 5145-5151.

[32] L. Cao, et al., "Antitumor and Immunomodulatory Activity of Arabinoxylans: A Major Constituent of Wheat Bran," International Journal of Biological Macromolecules, Vol. 48, No. 1, 2011, pp. 160-164. doi:10.1016/j.ijbiomac.2010.10.014

[33] A. P. P. Femia, et al., "Arabinoxylan-Oligosaccharides, (AXOS) Reduce Preneoplastic Lesions in the Colon of Rats Treated with 1,2-Dimethylhydrazine (DMH)," Euro- 
pean Journal of Nutrition, Vol. 49, No. 2, 2010, pp. 127132. doi:10.1007/s00394-009-0050-X

[34] D. Cholujova, J. Jakubikova and J. Sedlak, "Bio-branAugmented Maturation of Human Monocyte-Derived Dendritic Cells," Neoplasma, Vol. 56, No. 2, 2009, pp. 89-95. doi:10.4149/neo_2009_02_89

[35] E. Noaman, et al., "Antioxidant Potential by Arabinoxlan Rice Bran, MGN-3/Biobran, Represents a Mechanism for Its Oncostatic Effect against Murine Solid Ehrlich Carcinoma," Cancer Letters, Vol. 268, No. 2, 2008, pp. 348359. doi:10.1016/j.canlet.2008.04.012

[36] N. K. Badr El-Din, E. Noaman and M. Ghoneum, “In Vivo Tumor Inhibitory Effects of Nutritional Rice Bran Supplement MGN-3/Biobran on Ehrlich Carcnoma-Bearing Mice," Nutrition and Cancer, Vol. 60, No. 2, 2008, pp. 235-244. doi:10.1080/01635580701627285

[37] S. Gollapudi and M. Ghoneum, "MGN-3/Biobran, Modified Arabinoxylan from Rice Bran, Sensitizes Human Breast Cancer Cells to Chemotherapeutic Agent, Daunorubicin," Cancer Detection and Prevention, Vol. 32, No. 1, 2008, pp. 1-6. doi:10.1016/j.cdpp.2008.02.006

[38] M. Glei, et al., "Both Wheat, (Triticum aestivum) Bran Arabinoxylans and Gut Flora-Mediated Fermentation Products Protect Human Colon Cells from Genotoxic Activeties of 4-Hydroxynonenal and Hydrogen Peroxide," Journal of Agricultural and Food Chemistry, Vol. 54, No. 6, 2006, pp. 2088-2095. doi:10.1021/jf052768e

[39] M. Ghoneum and S. Gollapudi, "Synergistic Role of AraBinoxylan Rice Bran, (MGN-3/Biobran) in S. cerevisiae-Induced Apoptosis of Monolayer Breast Cancer MCF-7 Cells," Anticancer Research, Vol. 25, No. 6B, 2005, pp. 4187-4196.

[40] K. Ogawa, M. Takeuchi and N. Nakamura, "Immunological Effects of Partially Hydrolyzed Arabinoxylan from Corn Husk in Mice," Bioscience, Biotechnology and Biochemistry, Vol. 69, No. 1, 2005, pp. 19-25. doi:10.1271/bbb.69.19

[41] H. Maeda, et al., "Oral Administration of Hydrolyzed Rice Bran Prevents the Common Cold Syndrome in the Elderly Based on Its Immunomodulatory Action," Biofactors, Vol. 21, No. 1-4, 2004, pp. 185-187. doi:10.1002/biof.552210138

[42] M. Ghoneum and S. Abedi, "Enhancement of Natural Killer Cell Activity of Aged Mice by Modified Arabinoxylan Rice Bran, (MGN-3/Biobran)," Journal of Pharmacy and Pharmacology, Vol. 56, No. 12, 2004, pp. 1581-1588. doi:10.1211/0022357044922

[43] M. Ghoneum and A. Jewett, "Production of Tumor NecroSis Factor-Alpha and Interferon-Gamma from Human Peripheral Blood Lymphocytes by MGN-3, a Modified Ara-Binoxylan from Rice Bran, and Its Synergy with Inter-Leukin-2 in Vitro," Cancer Detection and Prevention, Vol. 24, No. 4, 2000, pp. 314-324.

[44] L. M. Ferrucci, et al., "Measurement of Spices and Seasonings in India: Opportunities for Cancer Epidemiology and Prevention," Asian Pacific Journal of Cancer Prevention, Vol. 11, No. 6, 2010, pp. 1621-1629.

[45] R. Kannappan, et al., "Neuroprotection by Spice-Derived
Nutraceuticals: You Are What You Eat!" Molecular Neurobiology, Vol. 44, No. 2, 2011, pp. 142-159. doi:10.1007/s12035-011-8168-2

[46] H. G. Zhang, et al., "Curcumin Reverses Breast Tumor Exosomes Mediated Immune Suppression of NK Cell Tumor Cytotoxicity," Biochimica et Biophysica Acta, Vol. 1773, No. 7, 2007, pp. 1116-1123. doi:10.1016/j.bbamcr.2007.04.015

[47] M. A. Bill, et al., "The Small Molecule Curcumin Analog FLLL32 Induces Apoptosis in Melanoma Cells via Stat3 Inhibition and Retains the Cellular Response to Cytokines with Anti-Tumor Activity," Molecular Cancer, Vol. 9, 2010, p. 165. doi:10.1186/1476-4598-9-165

[48] S. Bhaumik, M. D. Jyothi and A. Khar, "Differential Modulation of Nitric Oxide Production by Curcumin in Host Macrophages and NK Cells," FEBS Letters, Vol. 483, No. 1, 2000, pp. 78-82. doi:10.1016/S0014-5793, No. 00)02089-5

[49] M. A. Bill, et al., "Curcumin Induces Proapoptotic Effects against Human Melanoma Cells and Modulates the Cellu-Lar Response to Immunotherapeutic Cytokines," Molecular Cancer Therapeutics, Vol. 8, No. 9, 2009, pp. 2726-2735. doi:10.1158/1535-7163.MCT-09-0377

[50] G. Sa and T. Das, "Anti Cancer Effects of Curcumin: Cycle of Life and Death," Cell Division, Vol. 3, 2008, p. 14. doi:10.1186/1747-1028-3-14

[51] C. C. Li, et al., "A Study on the Construction, Expression and Immunosterility of Lagurus Laguru Zona Pellucida 3 DNA Vaccine pVAX1-sig-LTB-LZP3-C3d3," Chinese Journal of Cellular and Molecular Immunology, Vol. 27, No. 9, 2011, pp. 941-944.

[52] J. J. Lu, Y. J. Cai and J. Ding, "The Short-Time Treatment with Curcumin Sufficiently Decreases Cell Viability, Induces Apoptosis and Copper Enhances These Effects in Multidrug-Resistant K562/A02 Cells," Molecular and Cellular Biochemistry, Vol. 360, No. 1-2, 2012, pp. 253260. doi:10.1007/s11010-011-1064-2

[53] M. Bright-Gbebry, et al., "Use of Multivitamins, Folic Acid and Herbal Supplements among Breast Cancer Survivors: The Black Women's Health Study," BMC Complementary and Alternative Medicine, Vol. 11, 2011, p. 30. doi:10.1186/1472-6882-11-30

[54] C. A. Gonzalez, et al., "Fruit and Vegetable Intake and the Risk of Gastric Adenocarcinoma: A Reanalysis of the European Prospective Investigation into Cancer and Nutriation, (EPIC-EURGAST) Study after a Longer Follow-Upp," International Journal of Cancer, Vol. 131, No. 12, 2012, pp. 2910-2919. doi:10.1002/ijc.27565

[55] Y. Zhou, et al., "Consumption of Large Amounts of Allium Vegetables Reduces Risk for Gastric Cancer in a Meta-Analysis," Gastroenterology, Vol. 141, No. 1, 2011, pp. 80-89. doi:10.1053/j.gastro.2011.03.057

[56] T. Ghazanfari, et al., "In Vitro Cytotoxic Effect of Garlic Extract on Malignant and Nonmalignant Cell Lines," Immunopharmacol and Immunotoxicol, Vol. 33, No. 4, 2011, pp. 603-608. doi:10.3109/08923973.2011.551832

[57] M. S. Butt, M. T. Sultan and J. Iqbal, "Garlic: Nature's Protection against Physiological Threats," Critical Re- 
views in Food Science and Nutrition, Vol. 49, No. 6, 2009, pp. 538-551. doi:10.1080/10408390802145344

[58] H. Ishikawa, et al., "Aged Garlic Extract Prevents a Decline of Nk Cell Number and Activity in Patients with Advanced Cancer," Journal of Nutrition, Vol. 136, No. 3, 2006, pp. 816S-820S.

[59] D. L. Lamm and D. R. Riggs, "Enhanced Immunocompetence by Garlic: Role IN Bladder Cancer and Other Malign-Nancies," Journal of Nutrition, Vol. 131, No. 3s, 2001, pp. 1067S-1070S.

[60] D. L. Lamm and D. R. Riggs, "The Potential Application of Allium sativum, (Garlic) for the Treatment of Bladder Cancer," Urologic Clinics of North America, Vol. 27, No. 1, 2000, pp. 157-162, doi:10.1016/S0094-0143, No. 05)70243-3

[61] Z. M. Hassan, et al., "Immunomodulatory Affect of R10 Fraction of Garlic Extract on Natural Killer Activity," International Immunopharmacology, Vol. 3, No. 10-11, 2003, pp. 1483-1489. doi:10.1016/S1567-5769, No. 03)00161-9

[62] S. Kasuga, et al., "Pharmacologic Activities of Aged Garlic Extract IN Comparison with Other Garlic Preparations," Journal of Nutrition, Vol. 131, No. 3s, 2001, pp. 1080S-1084S.

[63] E. Kyo, et al., "Immunomodulatory Effects of Aged Garlic Extract," Journal of Nutrition, Vol. 131, No. 3s, 2001, pp. 1075S-1079S.

[64] Z. Tang, et al., "The Preventing Function of Garlic on Experimental Oral Precancer and Its Effect on Natural Killer Cells, T-Lymphocytes and Interleukin-2," Bulletin of Hunan Medical University, Vol. 22, No. 3, 1997, pp. 246-248.

[65] S.-H. Kim, A. Bommareddy and S. V. Singh, "Garlic Constituent Diallyl Trisulfide Suppresses X-Linked Inhibitor of Apoptosis Protein in Prostate Cancer Cellsin Culture and in Vivo," Cancer Prevention Research, Vol. 4, No. 6, 2011, pp. 897-906. doi:10.1158/1940-6207.CAPR-10-0323

[66] X. Wu, et al., "Proteasome Inhibitor Lactacystin Augments Natural Killer Cell Cytotoxicity of Myeloma via Downregu-Lation of Hla Class I," Biochemical and Biophysical Research Communications, Vol. 415, No. 1, 2011, pp. 187-192. doi:10.1016/j.bbrc.2011.10.057

[67] P. P. Wu, et al., "Diallyl Trisulfide (DATS) Inhibits Mouse Colon Tumor in Mouse CT-26 Cells Allograft Model in Vivo," Phytomedicine, Vol. 18, No. 8-9, 2011, pp. 672-676. doi:10.1016/j.phymed.2011.01.006

[68] P. P. Wu, et al., "Diallyl Sulfide Induces Cell Cycle Arrest and Apoptosis in Hela Human Cervical Cancer Cells through the p53, Caspase- and Mitochondria-Dependent Pathways," International Journal of Oncology, Vol. 38, No. 6, 2011, pp. 1605-1613.

[69] H. Javed, et al., "S-allyl Cysteine Attenuates Oxidative Stress Associated Cognitive Impairment and Neurodegeneration in Mouse Model of Streptozotocin-Induced Experimental Dementia of Alzheimer's Type," Brain Research, Vol. 1389, 2011, pp. 133-142. doi:10.1016/j.brainres.2011.02.072

[70] N. Morioka, et al., "A Protein Fraction from Aged Garlic
Extract Enhances Cytotoxicity and Proliferation of $\mathrm{Hu}-$ man Lymphocytes Mediated by Interleukin-2 and Concanavalin A," Cancer Immunology, Immunotherapy, Vol. 37, No. 5, 1993, pp. 316-322. doi:10.1007/BF01518454

[71] J. H. Cha, et al., "Allicin Inhibits Cell Growth and Induces Apoptosis in U87MG Human Glioblastoma Cells through an Erk-Dependent Pathway," Oncology Reports, Vol. 28, No. 1, 2012, pp. 41-48. doi:10.1007/BF01518454

[72] Y. M. Nkrumah-Elie, et al., "Diallyl trisulfide as an Inhibitor of Benzo (a) Pyrene-Induced Precancerous Carcinogenesis in MCF-10A Cells," Food and Chemical Toxicology, Vol. 50, No. 7, 2012, pp. 2542-2530. doi:10.1016/j.fct.2012.04.010

[73] J. E. Lee, et al., "Induction of Apoptosis with Diallyl Disul-Fide in Ags Gastric Cancer Cell Line," Journal of the Korean Surgical Society, Vol. 81, No. 2, 2011, pp. 85-95. doi:10.4174/jkss.2011.81.2.85

[74] J. H. Lee, et al., "1,25-Dihydroxyvitamin D3 Enhances NK Susceptibility of Human Melanoma Cells via Hsp60Mediated FAS Expression," European Journal of Immunology, Vol. 41, No. 10, 2011, pp. 2937-2946. doi:10.1002/eji.201141597

[75] Y. Lee, et al., "Anticancer Activity of S-AllylmercaptoL-Cysteine on Implanted Tumor of Human Gastric Cancer Cell," Biological and Pharmaceutical Bulletin, Vol. 34, No. 5, 2011, pp. 677-681. doi:10.1248/bpb.34.677

[76] Z. Liu, et al., "S-Allylcysteine Induces Cell Cycle Arrest and Apoptosis in Androgen-Independent Human Prostate Cancer Cells," Molecular Medicine Reports, Vol. 5, No. 2, 2012, pp. 439-443.

[77] E. J. Kim, et al., "Thiacremonone, a Sulfur Compound Isolated from Garlic, Attenuates Lipid Accumulation Partially Mediated via AMPK Activation in 3T3-L1 Adipocytes," The Journal of Nutritional Bioch, 2012. doi:10.1016/j.jnutbio.2011.10.008

[78] N. Morihara, M. Hayama and H. Fujii, "Aged Garlic Extract Scavenges Superoxide Radicals," Plant Foods for Human Nutrition, Vol. 66, No. 1, 2011, pp. 17-21. doi:10.1007/s11130-011-0216-6

[79] A. A. Powolny, et al., "The Garlic Constituent Diallyl Trisulfide Increases the Lifespan of C. Elegans via SKN-1 Activation," Experimental Gerontology, Vol. 46, No. 6, 2011, pp. 441-442. doi:10.1016/j.exger.2011.01.005

[80] R. Nepravishta, et al., "Oxidative Species and SGlutathionyl Conjugates in the Apoptosis Induction by Allyl Thiosulfate," FEBS Journal, Vol. 279, No. 1, 2012, pp. 154-167. doi:10.1111/j.1742-4658.2011.08407.x

[81] M. H. Pai, et al., "S-Allylcysteine Inhibits Tumour Progression and the Epithelial-Mesenchymal Transition in a Mouse Xenograft Model of Oral Cancer," British Journal of Nutrition, Vol. 108, No. 1, 2011, pp. 1-11.

[82] Y. Pei, et al., "Hydrogen Sulfide Mediates the Anti-Survival Effect of Sulforaphane on Human Prostate Cancer Cells," Toxicology and Applied Pharmacology, Vol. 257, No. 3, 2011, pp. 420-428. doi:10.1016/j.taapp.2011.09.026 
[83] Z. Wang, et al., "Resveratrol Induces Gastric Cancer Cell Apoptosis via Reactive Oxygen Species, but Independent of Sirtuin1," Clinical and Experimental Pharmacology and Physiology, Vol. 39, No. 3, 2012, pp. 227-232. doi:10.1111/j.1440-1681.2011.05660.x

[84] X. Wang, et al., "Aged Black Garlic Extract Induces Inhibittion of Gastric Cancer Cell Growth in Vitro and in Vivo," Molecular Medicine Reports, Vol. 5, No. 1, 2012, pp. 66-72.

[85] F. Wang, et al., "Long-Term Efficacy of 10-12 Years after Being Immunized with Chinese Hamster Ovary Cell Derived Hepatitis B Vaccine in Chinese Rural Communities," Vaccine, Vol. 30, No. 12, 2012, pp. 2051-2053. doi:10.1016/j.vaccine.2012.01.052

[86] M. O. Altonsy and S. C. Andrews, "Diallyl Disulphide, A Beneficial Component of Garlic Oil, Causes a Redistribution of Cell-Cycle Growth Phases, Induces Apoptosis, and Enhances Butyrate-Induced Apoptosis in Colorectal Adeno-Carcinoma Cells (HT-29)," Nutrition and Cancer, Vol. 63, No. 7, 2011, pp. 1104-1113. doi:10.1080/01635581.2011.601846

[87] C. Y. Chen, et al., "Diallyl Disulfide Induces $\mathrm{Ca}^{2+}$ Mobilization in Human Colon Cancer Cell Line SW480," Archives of Toxicology, Vol. 86, No. 2, 2012, pp. 231-238. doi:10.1007/s00204-011-0748-4

[88] K. Berginc and A. Kristl, "The Mechanisms Responsible for Garlic-Drug Interactions and Their in Vivo Relevance," Current Drug Metabolism, 2011.

[89] B. Akgul, et al., "Garlic Accelerates Red Blood Cell Turnover and Splenic Erythropoietic Gene Expression in Mice: Evidence for Erythropoietin-Independent Erythropoiesis," PLOS One, Vol. 5, No. 12, 2010, p. e15358. doi:10.1371/journal.pone.0015358

[90] C. Cerella, et al., "Chemical Properties and Mechanisms Determining the Anti-Cancer Action of Garlic-Derived or Ganic Sulfur Compounds," Anti-Cancer Agents in Medicinal Chemistry, Vol. 11, No. 3, 2011, pp. 267-271.

[91] C. Ma, et al., "Production, Characterisation and Immunogenicity of a Plant-Made Plasmodium Antigen-The 19 kDa C-Terminal Fragment of Plasmodium Yoelii Merozoite Surface Protein 1," Applied Microbiology and Biotechnology, Vol. 94, No. 1, 2012, pp. 151-161. doi:10.1007/s00253-011-3772-7

[92] J. L. Ma, et al., "Fifteen-Year Effects of Helicobacter Pylori, Garlic, and Vitamin Treatments on Gastric Cancer Incidence and Mortality," Journal of the National Cancer Institute, Vol. 104, No. 6, 2012, pp. 488-492. doi:10.1093/jnci/djs003

[93] Q. Ma and Y. Wang, "Comprehensive Analysis of the Prevalence of Hepatitis B Virus Escape Mutations in the Major Hydrophilic Region of Surface Antigen," Journal of Medical Virology, Vol. 84, No. 2, 2012, pp. 198-206. doi:10.1002/jmv.23183

[94] M. L. Antony and S. V. Singh, "Molecular Mechanisms and Targets of Cancer Chemoprevention by Garlic-Derived Bioactive Compound Diallyl Trisulfide," Indian Journal of Experimental Biology, Vol. 49, No. 11, 2011, pp. 805-816.
[95] M. Iciek, et al., "The Effects of Garlic-Derived Sulfur Compounds on Cell Proliferation, Caspase 3 Activity, Thiol Levels and Anaerobic Sulfur Metabolism in Human Hepato-Blastoma HepG2 Cells," Cell Biochemistry and Function, Vol. 30, No. 3, 2012, pp. 198-204. doi: $10.1002 /$ cbf. 1835

[96] H. Shirzad, F. Taji and M. Rafieian-Kopaei, "Correlation between Antioxidant Activity of Garlic Extracts and WEHI-164 Fibrosarcoma Tumor Growth in BALB/c Mice," Journal of Medicinal Food, Vol. 14, No. 9, 2011, pp. 969-974. doi:10.1089/jmf.2011.1594

[97] R. B. Walter, et al., "Vitamin, Mineral, and Specialty Supplements and Risk of Hematologic Malignancies in the Prospective VITamins and Lifestyle (VITAL) Study," Cancer Epidemiology, Biomarkers \& Prevention, Vol. 20, No. 10, 2011, pp. 2298-2308.

doi:10.1158/1055-9965.EPI-11-0494

[98] D. Liang, et al., "S-Allylmercaptocysteine Effectively Inhibits the Proliferation of Colorectal Cancer Cells under in Vitro and in Vivo Conditions," Cancer Letters, Vol. 310, No. 1, 2011, pp. 69-76. doi:10.1016/j.canlet.2011.06.019

[99] S. Karmakar, et al., "Molecular Mechanisms of AntiCancer Action of Garlic Compounds in Neuroblastoma," Anti-Cancer Agents in Medicinal Chemistry, Vol. 11, No. 4, 2011, pp. 398-407.

[100] Y. S. Huang, et al., "Diallyl Disulfide Inhibits the Proliferation of HT-29 Human Colon Cancer Cells by Inducing Differentially Expressed Genes," Molecular Medicine Reports, Vol. 4, No. 3, 2011, pp. 553-559.

[101] H. Hu, et al., "Identification of a Novel Function of Id-1 in Mediating the Anticancer Responses of Samc, a Water-Soluble Garlic Derivative, in Human Bladder Cancer Cells," Molecular Medicine Reports, Vol. 4, No. 1, 2011, pp. 9-16.

[102] A. Tsubura, et al., "Anticancer Effects of Garlic and Garlic-Derived Compounds for Breast Cancer Control," Anticancer Agents in Medicinal Chemistry, Vol. 11, No. 3, 2011, pp. 249-253.

[103] C. H. Kaschula, et al., "Anti-Proliferation Activity of Synthetic Ajoene Analogues on Cancer Cell-Lines," Anticancer Agents in Medicinal Chemistry, Vol. 11, No. 3, 2011, pp. 260-266.

[104] E. Viry, et al., "Antiproliferative Effect of Natural Tetrasul-Fides in Human Breast Cancer Cells Is Mediated Through the Inhibition of the Cell Division Cycle 25 Phosphatases," International Journal of Oncology, Vol. 38, No. 4, 2011, pp. 1103-1111.

[105] V. Karagianni, et al., "Risk Factors for Colorectal Polyps: Findings from a Greek Case-Control Study," Revista Medico-Chirurgicala a Societatii de Medici Si Naturalisti Din Iasi, Vol. 114, No. 3, 2010, pp. 662-670.

[106] T. Chihara, et al., "Inhibition of 1,2-DimethylhydrazineInduced Mucin-Depleted Foci and O(6)-Methylguanine DNA Adducts in the Rat Colorectum by Boiled Garlic Powder," Asian Pacific Journal of Cancer Prevention, Vol. 11, No. 5, 2010, pp. 1301-1304.

[107] E. Padilla-Camberos, et al., "Antitumoral Activity of Al- 
licin in Murine Lymphoma L5178Y," Asian Pacific Journal of Cancer Prevention, Vol. 11, No. 5, 2010, pp. 1241-1244.

[108] S. Salem, et al., "Major Dietary Factors and Prostate Cancer Risk: A Prospective Multicenter Case-Control Study," Nutrition and Cancer, Vol. 63, No. 1, 2011, pp. 21-27.

[109] N. Ferrari, et al., "Diet-Derived Phytochemicals: From Cancer Chemoprevention to Cardio-Oncological Prevention," Current Drug Targets, Vol. 12, No. 13, 2011, pp. 1909-1924. doi:10.2174/138945011798184227

[110] B. Ray, N. B. Chauhan and D. K. Lahiri, "The Aged Garlic Extract (AGE) and One of Its Active Ingredients S-Allyl-L-Cysteine (SAC) as Potential Preventive and Therapeutic Agents for Alzheimer's Disease (AD)," Current Drug Targets, Vol. 18, No. 22, 2011, pp. 3306-3313. doi:10.2174/092986711796504664

[111] K. C. Lai, et al., "Diallyl Sulfide, Diallyl Disulfide, and Diallyl Trisulfide Inhibit Migration and Invasion in $\mathrm{Hu}-$ man Colon Cancer Colo 205 Cells through the Inhibition of Matrix Metalloproteinase-2, -7, and -9 Expressions," Environmental Toxicology, Vol. 3, 2011. doi:10.1002/tox.20737

[112] M. Miroddi, F. Calapai and G. Calapai, "Potential Beneficial Effects of Garlic in Oncohematology," MiniReviews in Medicinal Chemistry, Vol. 11, No. 6, 2011, pp. 461-472. doi:10.2174/138955711795843293

[113] A. Ogita, K. Fujita and T. Tanaka, "Enhancing Effects on Vacuole-Targeting Fungicidal Activity of Amphotericin B," Frontiers in Microbiology, Vol. 3, 2012, p. 100.

[114] R. Marik, et al., "Potent Genistein Derivatives as Inhibitors of Estrogen Receptor Alpha-Positive Breast Cancer," Cancer Biology \& Therapy, Vol. 11, No. 10, 2011, pp. 883-892. doi:10.4161/cbt.11.10.15184

[115] T. L. Guo, et al., "Genistein Modulates Splenic Natural Killer Cell Activity, Antibody-Forming Cell Response, and Phenotypic Marker Expression in F(0) and F(1) Generations of Sprague-Dawley Rats," Toxicology and Applied Pharmacology, Vol. 181, No. 3, 2002, pp. 219-227.

[116] M. F. Ullah, et al., "Soy Isoflavone Genistein Induces Cell Death in Breast Cancer Cells through Mobilization of Endogenous Copper Ions and Generation of Reactive Oxygen Species," Molecular Nutrition \& Food Research, Vol. 55, No. 4, 2011, pp. 553-559. doi: $10.1002 / \mathrm{mnfr} .201000329$

[117] R. J. Zhou, et al., "Anti-Tumor Effects of All-Trans Retinoic Acid Are Enhanced by Genistein," Cell Biochemistry and Biophysics, Vol. 62, No. 1, 2012, pp. 177184.doi:10.1007/s12013-011-9279-0

[118] X. Yu, et al., "Anti-Angiogenic Genistein Inhibits VEGFInduced Endothelial Cell Activation by Decreasing PTK Activity and Mapk Activation," Medical Oncology, Vol. 29, No. 1, 2012, pp. 349-357. doi:10.1007/s12032-010-9770-2

[119]F. Polito, et al., "Genistein Aglycone, a Soy-Derived Isoflavone, Improves Skin Changes Induced by Ovariectomy in Rats," British Journal of Pharmacology, Vol. 165, No. 4, 2012, pp. 994-1005. doi:10.1111/j.1476-5381.2011.01619.x
[120] Y. Zhang and H. Chen, "Genistein Attenuates WNT Signaling by Up-Regulating sFRP2 in a Human Colon Cancer Cell Line," Experimental Biology and Medicine (Maywood), Vol. 236, No. 6, 2011, pp. 714-722. doi:10.1258/ebm.2011.010347

[121] M. B. van Duursen, et al., "Genistein Induces Breast Cancer-Associated Aromatase and Stimulates EstrogenDependent Tumor Cell Growth in Vitro Breast Cancer Model," Toxicology, Vol. 289, No. 2-3, 2011, pp. 67-73. doi:10.1016/j.tox.2011.07.005

[122] C. Sanchez, et al., "Chemotherapy Sensitivity Recovery of Prostate Cancer Cells by Functional Inhibition and Knock down of Multidrug Resistance Proteins," Prostate, Vol. 71, No. 16, 2011, pp. 1810-1817. doi: $10.1002 /$ pros. 21398

[123] W. Qi, et al., "Genistein Inhibits Proliferation of Colon Cancer Cells by Attenuating a Negative Effect of Epidermal Growth Factor on Tumor Suppressor FOXO3 Activity," BMC Cancer, Vol. 11, 2011, pp. 219. doi:10.1186/1471-2407-11-219

[124] G. Ji, et al., "Anti-Inflammatory Effect of Genistein on Non-Alcoholic Steatohepatitis Rats Induced by High Fat Diet and Its Potential Mechanisms," International Immunopharmacology, Vol. 11, No. 6, 2011, pp. 762-768. doi:10.1016/j.intimpp.2011.01.036

[125] D. Hess and R. A. Igal, "Genistein Downregulates Denovo Lipid Synthesis and Impairs Cell Proliferation in Human Lung Cancer Cells," Experimental Biology and Medicine, Vol. 236, No. 6, 2011, pp. 707-713. doi:10.1258/ebm.2011.010265

[126] S. de Assis, et al., "Protective Effects of Prepubertal Genistein Exposure on Mammary Tumorigenesis Are Depend-ENT on Brcal Expression," Cancer Prevention Research, Vol. 4, No. 9, 2011, pp. 1436-1448. doi:10.1158/1940-6207.CAPR-10-0346

[127] F. G. Bottone Jr. and B. Alston-Mills, "The Dietary Compounds Resveratrol and Genistein Induce Activating Transcription Factor 3 While Suppressing Inhibitor of DNA Binding/Differentiation-1," Journal of Medicinal Food, Vol. 14, No. 6, 2011, pp. 584-593. doi:10.1089/jmf.2010.0110

[128] Y. Zhang, et al., "Genistein Inhibits Osteolytic Bone Metastasis and Enhances Bone Mineral in Nude Mice," Environmental Toxicology and Pharmacology, Vol. 30, No. 1, 2010, pp. 37-44. doi:10.1016/j.etapp.2010.03.016

[129] M. Yamasaki, et al., "Genistein Induced Apoptotic Cell Death in Adult T-Cell Leukemia Cells through Estrogen Receptors," Bioscience, Biotechnology, and Biochemistry, Vol. 74, No. 10, 2010, pp. 2113-2115. doi:10.1271/bbb.100359

[130] I. Hwang, et al., "An Acidic Polysaccharide of Panax Ginseng Ameliorates Experimental Autoimmune EncephaloMyelitis and Induces Regulatory T Cells," Immunology Letters, Vol. 138, No. 2, 2011, pp. 169-178. doi:10.1016/j.imlet.2011.04.005

[131] J. L. Elam, et al., "Methodological Issues in the Investigation of Ginseng as an Intervention for Fatigue," Clinical Nurse Specialist, Vol. 20, No. 4, 2006, pp. 183-189. doi:10.1097/00002800-200607000-00007 
[132] F. Y. Xie, Z. F. Zeng and H. Y. Huang, "Clinical Observation on Nasopharyngeal Carcinoma Treated with Combined Therapy of Radiotherapy and Ginseng Polysaccharide Injection," Chinese Journal of Integrated Traditional and Western Medicine, Vol. 21, No. 5, 2001, pp. 332-334.

[133] H. Nakata, et al., "Inhibitory Effects of Ginsenoside RH2 on Tumor Growth in Nude Mice Bearing Human Ovarian Cancer Cells," Japanese Journal of Cancer Research, Vol. 89, No. 7, 1998, pp. 733-740. doi:10.1111/j.1349-7006.1998.tb03278.x

[134] D. M. See, et al., "In Vitro Effects of Echinacea and Ginseng on Natural Killer and Antibody-Dependent Cell Cytotoxicity in Healthy Subjects and Chronic Fatigue Syndrome or Acquired Immunodeficiency Syndrome Patients," Immunopharmacology, Vol. 35, No. 3, 1997, pp. 229-235. doi:10.1016/S0162-3109, No. 96)00125-7

[135] S. Y. Lin, L. M. Liu and L. C. Wu, "Effects of Shenmai Injection on Immune Function in Stomach Cancer Patients after Chemotherapy," Chinese Journal of Integrated Traditional and Western Medicine, Vol. 15, No. 8, 1995, pp. 451-453.

[136] Y. S. Yun, et al., "Inhibition of Autochthonous Tumor by Ethanol Insoluble Fraction from Panax Ginseng as an Immunomodulator," Planta Medica, Vol. 59, No. 6, 1993, pp. 521-524. doi:10.1055/s-2006-959752

[137] F. Scaglione, et al., "Immunomodulatory Effects of Two Extracts of Panax Ginseng C. A. Meyer," Drugs under Experimental and Clinical Research, Vol. 16, No. 10, 1990, pp. 537-542.

[138] B. Kenarova, et al., "Immunomodulating Activity of Ginsenoside RG1 from Panax Ginseng," The Japanese Journal of Pharmacology, Vol. 54, No. 4, 1990, pp. 447454. doi:10.1254/jipp. 54.447

[139] S. P. Wasser, "Medicinal Mushrooms as a Source of Antitumor and Immunomodulating Polysaccharides," $A p$ plied Microbiology and Biotechnology, Vol. 60, No. 3, 2002, pp. 258-274. doi:10.1007/s00253-002-1076-7

[140] T. Mitamura, et al., "Effects of Lentinan on Colorectal Carcinogenesis in Mice with Ulcerative Colitis," Oncology Reports, Vol. 7, No. 3, 2000, pp. 599-601.

[141] M. Suzuki, et al., "Curative Effects of Combination Therapy with Lentinan and Interleukin-2 against Established Murine Tumors, and the Role of CD8-Positive T cells," Cancer Immunology, Immunotherapy, Vol. 38, No. 1, 1994, pp. 1-8. doi:10.1007/BF01517163

[142] M. Suzuki, et al., "Reconstitution of Anti-Tumor Effects of Lentinan in Nude Mice: Roles of Delayed-Type Hypersensitivity Reaction Triggered by CD4-Positive T cell Clone in the Infiltration of Effector Cells into Tumor," Japanese Journal of Cancer Research, Vol. 85, No. 4, 1994, pp. 409-417. doi:10.1111/j.1349-7006.1994.tb02374.x

[143] V. Vetvicka, et al., "Enhancing Effects of New Biological Response Modifier Beta-1,3 Glucan Sulfate PS3 on Immune Reactions," Biomedicine \& Pharmacotherapy, Vol. 62, No. 5, 2008, pp. 283-288. doi:10.1016/j.biopha.2007.05.011

[144] V. Vetvicka, et al., "Immunological Effects of Yeast- and Mushroom-Derived Beta-Glucans," Journal of Medicinal
Food, Vol. 11, No. 4, 2008, pp. 615-622. doi:10.1089/jmf.2007.0588

[145] J. Wang, Z. D. Zhou and D. J. Xia, "Study on Effect of Lentinan in Enhancing Anti-Tumor Action of Dendritic Cytoma Vaccine and Its Mechanism," Chinese Journal of Integrated Traditional and Western Medicine, Vol. 27, No. 1, 2007, pp. 60-64.

[146] V. Vetvicka and J. C. Yvin, "Effects of Marine Beta-1,3 Glucan on Immune Reactions," International Immunopharmacology, Vol. 4, No. 6, 2004, pp. 721-730. doi:10.1016/j.intimpp.2004.02.007

[147] M. L. Ng and A. T. Yap, "Inhibition of Human Colon Carcinoma Development by Lentinan from Shiitake Mushrooms (Lentinus edodes)," Journal of Alternative and Complementary Medicine, Vol. 8, No. 5, 2002, pp. 581-589. doi:10.1089/107555302320825093

[148] K. Hamano, et al., "The Preoperative Administration of Lentinan Ameliorated the Impairment of Natural Killer Activity after Cardiopulmonary Bypass," International Journal of Immunopharmacology, Vol. 21, No. 8, 1999, pp. 531-540. doi:10.1016/S0192-0561, No. 99)00033-8

[149] S. B. Han, et al., "Characteristic Immunostimulation by Angelan Isolated from Angelica Gigas Nakai," Immunopharmacology, Vol. 40, No. 1, 1998, pp. 39-48. doi:10.1016/S0162-3109, No. 98)00026-5

[150] J. F. Li, J. W. Guo and X. F. Huang, "Study on the Enhancing Effect of Polyporus Polysaccharide, Mycobacterium Polysaccharide and Lentinan on Lymphokine-Activated Killer Cell Activity in Vitro," Chinese Journal of Integrated Traditional and Western Medicine, Vol. 16, No. 4, 1996, pp. 224-226.

[151] M. Rafique and W. Adachi, "Effects of Intraportal Administration of Chemoimmunotherapeutic Agents on Natural Killer Cell Activity in the Rat Liver," Journal of Surgical Oncology, Vol. 60, No. 3, 1995, pp. 154-159. doi:10.1002/jso.2930600304

[152] H. Matsuoka, et al., "Usefulness of Lymphocyte Subset Change as an Indicator for Predicting Survival Time and Effectiveness of Treatment with the Immunopotentiator Lentinan," Anticancer Research, Vol. 15, No. 5B, 1995, pp. 2291-2296.

[153] S. Hazama, et al., "Clinical Effects and Immunological Analysis of Intraabdominal and Intrapleural Injection of Lentinan for Malignant Ascites and Pleural Effusion of Gastric Carcinoma," Japanese Journal of Cancer and Chemotherapy, Vol. 22, No. 11, 1995, pp. 1595-1597.

[154] E. Kobayashi, et al., "KRN7000, a Novel Immunomodulator, and Its Antitumor Activities," Ology Research, Vol. 7, No. 10-11, 1995, pp. 529-534.

[155] H. Morinaga, et al., "An in Vivo Study of Hepatic and Splenic Interleukin-1 Beta mRNA Expression Following Oral PSK or LEM Administration," Japanese Journal of Cancer Research, Vol. 85, No. 12, 1994, pp. 1298-1303. doi:10.1111/j.1349-7006.1994.tb02943.x

[156] J. Hamuro, et al., "Synergistic Antimetastatic Effects of Lentinan and Interleukin 2 with Pre- and Post-Operative Treatments," Japanese Journal of Cancer Research, Vol. 85, No. 12, 1994, pp. 1288-1297. 
doi:10.1111/j.1349-7006.1994.tb02942.x

[157] Z. B. Yang, "Effects of Pretreatment with Lentinan or Krestin on Antitumor Effector Cell Activities Suppressed by Cyclophosphamide," Hokkaido Journal of Medical Science, Vol. 69, No. 1, 1994, pp. 137-145.

[158] M. Tani, et al., "Augmentation of Lymphokine-Activated Killer Cell Activity by Lentinan," Anticancer Research, Vol. 13, No. 5C, 1993, pp. 1773-1776.

[159] S. Arinaga, et al., "Enhanced Induction of LymphokineActivated Killer Activity after Lentinan Administration in Patients with Gastric Carcinoma," International Journal of Immunopharmacology, Vol. 14, No. 4, 1992, pp. 535539. doi:10.1016/0192-0561, No. 92)90114-Z

[160] M. Tani, et al., "In Vitro Generation of Activated Natural Killer Cells and Cytotoxic Macrophages with Lentinan," European Journal of Clinical Pharmacology, Vol. 42, No. 6, 1992, pp. 623-627. doi:10.1007/BF00265926

[161] M. Takahashi, et al., "Two-Color Flow Cytometric Analysis of Splenic Lymphocyte Subpopulations in Patients with Gastric Cancer," Surgery Today, Vol. 22, No. 1, 1992, pp. 35-39. doi:10.1007/BF00326123

[162] T. Fujimoto, et al., "Evaluation of Basic Procedures for Adoptive Immunotherapy for Gastric Cancer," Biotherapy, Vol. 5, No. 2, 1992, pp. 153-163. doi:10.1007/BF02171701

[163] M. Oka, et al., "Immunological Analysis and Clinical Effects of Intraabdominal and Intrapleural Injection of Lentinan for Malignant Ascites and Pleural Effusion," Biotherapy, Vol. 5, No. 2, 1992, pp. 107-112. doi:10.1007/BF02171695

[164] H. Tanabe, N. Imai and K. Takechi, "Studies on Usefulness of Postoperative Adjuvant Chemotherapy with Lentinan in Patients with Gastrointestinal Cancer," Journal of Japan Society for Magazine Subscription, Vol. 25, No. 8, 1990, pp. 1657-1667.

[165] M. Suzuki, et al., "Induction of Endogenous Lymphokine-Activated Killer Activity by Combined Administration of Lentinan and Interleukin 2," International Journal of Immunopharmacology, Vol. 12, No. 6, 1990, pp. 613-623. doi:10.1016/0192-0561, No. 90)90098-8

[166] H. Shimizu, M. Inoue and O. Tanizawa, "Adoptive Cellular Immunotherapy to the Endometrial Carcinoma Cell Line Xenografts in Nude Mice," Gynecologic Oncology, Vol. 34, No. 2, 1989, pp. 195-199. doi:10.1016/0090-8258, No. 89)90141-8

[167] S. Yoshino, et al., "Effect of Intrapleural and/or Intraperitoneal Lentinan Therapy on Carcinomatous Pleuritis and Peritonitis with Special Reference to Immunological Evaluation," Nihon Geka Hokan, Vol. 58, No. 3, 1989, pp. 310-319.

[168] K. Yamasaki, et al., "Synergistic Induction of Lymphokine, (IL-2)-Activated Killer Activity by IL-2 and the Polysaccharide Lentinan, and Therapy of Spontaneous Pulmonary Metastases," Cancer Immunology, Immunotherapy, Vol. 29, No. 2, 1989, pp. 87-92. doi:10.1007/BF00199282

[169] T. Inagaki, K. Morise and H. Matsunaga, "Effects of Endoscopic Intratumoral Injection of Lentinan in Patients with Gastric Cancer," Japanese Journal of Cancer and Chemotherapy, Vol. 15, No. 2, 1988, pp. 319-324.

[170] G. Peter, et al., "Effects of Lentinan on Cytotoxic Functions of Human Lymphocytes," Immunopharmacology and Immunotoxicology, Vol. 10, No. 2, 1988, pp. 157-163. doi:10.3109/08923978809014330

[171] M. Akimoto, T. Nishihira and M. Kasai, "Modulation of the Anti-Tumor Effect of BRM under Various Nutritional or Endocrine Conditions," Japanese Journal of Cancer and Chemotherapy, Vol. 13, No. 4, 1986, pp. 1270-1276.

[172]H. Miyakoshi, T. Aoki and M. Mizukoshi, "Acting Mechanisms of Lentinan in Human-II. Enhancement of Non-Specific Cell-Mediated Cytotoxicity as an Interferon Inducer," International Journal of Immunopharmacology, Vol. 6, No. 4, 1984, pp. 373-379. doi:10.1016/0192-0561, No. 84)90057-2

[173] M. Amino, et al., "Studies on the Effect of Lentinan on Human Immune System. II. In Vivo effect on NK Activity, MLR Induced Killer Activity and Pha Induced Blastic Response of Lymphocytes in Cancer Patients," Japanese Journal of Cancer and Chemotherapy, Vol. 10, No. 9, 1983, pp. 2000-2006.

[174] K. Kurita, et al., "Synthesis and Macrophage Activation of Lentinan-Mimic Branched Amino Polysaccharides: Curdlans Having N-Acetyl-D-Glucosamine Branches," Biomacromolecules, Vol. 12, No. 6, 2011, pp. 2267-2274. doi: $10.1021 / \mathrm{bm} 200353 \mathrm{~m}$

[175] K. Harada, et al., "Effects of Lentinan Alone and in Combination with Fluoropyrimidine Anticancer Agent on Growth of Human Oral Squamous Cell Carcinoma in Vitro and in Vivo," International Journal of Oncology, Vol. 37, No. 3, 2010, pp. 623-631. doi:10.3892/ijo_00000711

[176] E. McCormack, et al., "Lentinan: Hematopoietic, Immunological, and Efficacy Studies in a Syngeneic Model of Acute Myeloid Leukemia," Nutrition and Cancer, Vol. 62, No. 5, 2010, pp. 574-583. doi:10.1080/01635580903532416

[177] X. Wang, et al., "Effects of Potential Calcium Sensing Receptor Inducers on Promoting Chemosensitivity of Human Colon Carcinoma Cells," International Journal of Oncology Vol. 36, No. 6, 2010, pp. 1573-1580.

[178]Z. Wang and H. Chen, "Genistein Increases Gene Expression by Demethylation of Wnt5a Promoter in Colon Cancer Cell Line SW1116," Anticancer Research, Vol. 30, No. 11, 2010, pp. 4537-4545.

[179] N. Isoda, et al., "Clinical Efficacy of Superfine Dispersed Lentinan, No. Beta-1,3-Glucan) in Patients with Hepatocellular Carcinoma," Hepatogastroenterology, Vol. 56, No. 90, 2009, pp. 437-441.

[180] S. Maruyama, et al., "Anti Tumor Activities of Lentinan and Micellapist in Tumor-Bearing Mice," Japanese Journal of Cancer and Chemotherapy, Vol. 33, No. 12, 2006, pp. 1726-1729.

[181] J. Hamuro, "Anticancer Immunotherapy with Perorally Effective Lentinan," Japanese Journal of Cancer and Chemotherapy, Vol. 32, No. 8, 2005, pp. 1209-1215.

[182]H. Mushiake, et al., "Dendritic Cells Might Be One of 
Key Factors for Eliciting Antitumor Effect by Chemoimmunotherapy in Vivo," Cancer Immunology, Immunotherapy, Vol. 54, No. 2, 2005, pp. 120-128.

doi:10.1007/s00262-004-0585-X

[183] S. Yoshino, et al., "Immunoregulatory Effects of the Antitumor Polysaccharide Lentinan on TH1/TH2 Balance in Patients with Digestive Cancers," Anticancer Research, Vol. 20, No. 6C, 2000, pp. 4707-4711.

[184] F. Takatsuki, et al., "Improvement of Erythroid Toxicity by Lentinan and Erythropoietin in Mice Treated with Chemotherapeutic Agents," Experimental Hematology, Vol. 24, No. 3, 1996, pp. 416-422.

[185] S. Goto, et al., “A Case Report of Recurrent Cervical Cancer Which Responded to a Combination of Biological Therapies," European Journal of Gynaecological Oncology, Vol. 15, No. 3, 1994, pp. 235-240.

[186] S. Braedel-Ruoff, "Immunomodulatory Effects of Viscum album Extracts on Natural Killer Cells: Review of Clinical Trials," Forsch Komplementmed, Vol. 17, No. 2, 2010, pp. 63-73. doi:10.1159/000288702

[187] E. Gunsilius, J. Clausen and G. Gastl, "Palliative Immunotherapy of Cancer," Therapeutische Umschau, Vol. 58, No. 7, 2001, pp. 419-424. doi: $10.1024 / 0040-5930.58 .7 .419$

[188] A. Bussing, et al., "Development of Lymphocyte Subsets in Tumor Patients after Subcutaneous Administration of Mistletoe Extracts," Forsch Komplementarmed, Vol. 6, No. 4, 1999, pp. 196-204. doi:10.1159/000021253

[189] W. Dohmen, M. Breier and U. Mengs, "Cellular Immunomodulation and Safety of Standardized Aqueous Mistletoe Extract PS76A2 in Tumor Patients Treated for 48 Weeks," Anticancer Research, Vol. 24, No. 2C, 2004, pp. 1231-1237.

[190] T. Hajto and C. Lanzrein, "Natural Killer and AntibodyDependent Cell-Mediated Cytotoxicity Activities and Large Granular Lymphocyte Frequencies in Viscum album-Treated Breast Cancer Patients," Oncology, Vol. 43, No. 2, 1986, pp. 93-97. doi:10.1159/000226342

[191] J. Hauer and F. A. Anderer, "Mechanism of Stimulation of Human Natural Killer Cytotoxicity by Arabinogalactan from Larix Occidentalis," Cancer Immunology, Immunotherapy, Vol. 36, No. 4, 1993, pp. 237-244. doi:10.1007/BF01740905

[192] G. Maier and H. H. Fiebig, "Absence of Tumor Growth Stimulation in a Panel of 16 Human Tumor Cell Lines by Mistletoe Extracts in Vitro," Anticancer Drugs, Vol. 13, No. 4, 2002, pp. 373-379. doi:10.1097/00001813-200204000-00006

[193] M. Schink, "Mistletoe Therapy for Human Cancer: The Role of the Natural Killer Cells," Anticancer Drugs, Vol. 8, No. 1S, 1997, pp. S47-S51. doi:10.1097/00001813-199704001-00011

[194] A. Thies, et al., "Binding of Mistletoe Lectins to Cutaneous Malignant Melanoma: Implications for Prognosis and Therapy," Anticancer Research, Vol. 21, No. 4B, 2001, pp. 2883-2887.

[195] C. Guerra, et al., "Control of Mycobacterium Tuberculosis Growth by Activated Natural Killer Cells," Clinical \&
Experimental Immunology, Vol. 168, No. 1, 2012, pp. 142-152. doi:10.1111/j.1365-2249.2011.04552.x

[196] M. Ardolino, et al., "DNAM-1 Ligand Expression on AG-Stimulated T Lymphocytes Is Mediated by ROS-Dependent Activation of DNA-Damage Response: Relevance for NK-T Cell Interaction," Blood, Vol. 117, No. 18, 2011, pp. 4778-4786. doi:10.1182/blood-2010-08-300954

[197] I. A. Gamalei, et al., "N-Acetylcysteine-Induced Reduction in Susceptibility of Transformed and Embryonic Cells to Lytic Activity of Natural Killer Cells," Tsitologiia, Vol. 52, No. 7, 2010, pp. 555-561.

[198] L. Weiss, et al., "N-Acetylcysteine Mildly Inhibits the Graft-vs.-Leukemia Effect but Not the Lymphokine Activated Cells (LAK) Activity," Transplant Immunology, Vol. 17, No. 3, 2007, pp. 198-202. doi:10.1016/j.trim.2006.10.005

[199] N. A. Filatova, K. M. Kirpichnikova and I. A. Gamalei, "N-Acetylcysteine Reduces Transformed 3T3-SV40 Fibroblast Sensitivity to Lysis by Natural Killer Cells," Tsitologiia, Vol. 48, No. 5, 2006, pp. 438-442.

[200] J. Zhao and X. J. Liu, "Antioxidative and Immunomodulatory Role of Melatonin, Sodium Selenite, N-Acetyl-LCysteine and Quercetin on Human Umbilical Blood," Pharmazie, Vol. 60, No. 9, 2005, pp. 683-688.

[201] N. Guayerbas, et al., "A Diet Supplemented with Thiolic Anti-Oxidants Improves Leucocyte Function in Two Strains of Prematurely Ageing Mice," Clinical and Experimental Pharmacology and Physiology, Vol. 29, No. 11, 2002, pp. 1009-1014. doi:10.1046/j.1440-1681.2002.03758.x

[202] M. de La Fuente, et al., "The Amount of Thiolic Antioxidant Ingestion Needed to Improve Several Immune Functions Is Higher in Aged than in Adult Mice," Free Radical Research, Vol. 36, No. 2, 2002, pp. 119-126. doi:10.1080/10715760290006439

[203] M. Viora, et al., "Redox Imbalance and Immune Functions: Opposite Effects of Oxidized Low-Density Lipoproteins and N-Acetylcysteine," Immunology, Vol. 104, No. 4, 2001, pp. 431-438. doi:10.1046/j.1365-2567.2001.01334.x

[204] S. Kojima, et al., "Elevation of Glutathione Induced by Low-Dose Gamma Rays and Its Involvement in Increased Natural Killer Activity," Radiation Research, Vol. 157, No. 3, 2002, pp. 275-280.

doi:10.1667/0033-7587,No.2002)157[0275:EOGIBL]2.0. $\mathrm{CO} ; 2$

[205]K. Dobashi, et al., "Regulation of LPS Induced IL-12 Production by IFN-Gamma and IL-4 through Intracellular Glutathione Status in Human Alveolar Macrophages," Clinical \& Experimental Immunology, Vol. 124, No. 2, 2001, pp. 290-296. doi:10.1046/j.1365-2249.2001.01535.x

[206] R. Breitkreutz, et al., "Improvement of Immune Functions in HIV Infection by Sulfur Supplementation: Two Randomized Trials," Journal of Molecular Medicine, Vol. 78, No. 1, 2000, pp. 55-62. doi:10.1007/s001090050382

[207] W. Droge and R. Breitkreutz, "Glutathione and Immune Function," Proceedings of the Nutrition Society, Vol. 59, 
No. 4, 2000, pp. 595-600. doi:10.1017/S0029665100000847

[208] M. D. Ferrandez, et al., "Effects in Vitro of Several Antioxidants on the Natural Killer Function of Aging Mice," Experimental Gerontology, Vol. 34, No. 5, 1999, pp. 675-685. doi:10.1016/S0531-5565, No. 99)00009-1

[209] K. Furuke, et al., "Fas Ligand Induction in Human NK Cells Is Regulated by Redox through a Calcineurin-Nuclear Factors of Activated T Cell-Dependent Pathway," The Journal of Immunology, Vol. 162, No. 4, 1999, pp. 1988-1993.

[210] S. Suyuki, et al., "N-Acetylcysteine Improves Cytotoxic Activity of Cirrhotic Rat Liver-Associated Mononuclear Cells," International Immunology, Vol. 10, No. 10, 1998, pp. 1501-1508. doi:10.1093/intimm/10.10.1501

[211] A. Yamauchi and E. T. Bloom, "Control of Cell Cycle Progression in Human Natural Killer Cells through Redox Regulation of Expression and Phosphorylation of Retinoblastoma Gene Product Protein," Blood, Vol. 89, No. 11, 1997, pp. 4092-4099.

[212] T. Chiba, et al., "Fas-Mediated Apoptosis Is Modulated by Intracellular Glutathione in Human T Cells," European Journal of Immunology, Vol. 26, No. 5, 1996, pp. 11641169. doi:10.1002/eji.1830260530

[213] W. Malorni, et al., "Thiol Supplier N-Acetylcysteine Enhances Conjugate Formation between Natural Killer Cells and K562 or U937 Targets but Increases the Lytic Function Only against the Latter," Immunology Letters, Vol. 43, No. 3, 1994, pp. 209-214. doi:10.1016/0165-2478, No. 94)90225-9

[214] C. Y. Yim, et al., "Use of N-Acetyl Cysteine to Increase Intracellular Glutathione during the Induction of Antitumor Responses by IL-2," The Journal of Immunology, Vol. 152, No. 12, 1994, pp. 5796-805.

[215] A. Tsuji, et al., "Immune Stimulatory and Anti-Tumour Properties of Haemin," Clinical \& Experimental Immunology, Vol. 93, No. 3, 1993, pp. 308-312. doi:10.1111/j.1365-2249.1993.tb08177.x

[216] V. Vetvicka and J. Vetvickova, "Combination of Glucan, Resveratrol and Vitamin C Demonstrates Strong AntiTumor Potential," Anticancer Research, Vol. 32, No. 1, 2012, pp. 81-87.

[217] H. Miki, et al., "Resveratrol Induces Apoptosis via Rostriggered Autophagy in Human Colon Cancer Cells," International Journal of Oncology, Vol. 40, No. 4, 2012, pp. 1020-1028.

[218] R. Di Franco, et al., "Skin Toxicity from External Beam Radiation Therapy in Breast Cancer Patients: Protective Effects of Resveratrol, Lycopene, Vitamin C and Anthocianin $\left(\right.$ Ixor $^{\circledR}$ )," Radiation Oncology, Vol. 7, 2012, p. 12. doi:10.1186/1748-717X-7-12

[219] J. H. Kim, C. Chen and A. N. T. Kong, "Resveratrol Inhibits Genistein-Induced Multi-Drug Resistance Protein 2 (MRP2) Expression in HepG2 Cells," Archives of Biochemistry and Biophysics, Vol. 512, No. 2, 2011, pp. 160166. doi:10.1016/j.abb.2011.06.004

[220] Y. Hiroto, et al., "Resveratrol, a Phytoestrogen Found in Red Wine, Down-Regulates Protein S Expression in
HepG2 Cells," Thrombosis Research, Vol. 127, No. 1, 2011, pp. e1-e7. doi:10.1016/j.thromres.2010.09.010

[221] B. Shao, et al., "Proteomics Analysis of Human Umbilical Vein Endothelial Cells Treated with Resveratrol," Amino Acids, Vol. 43, No. 4, 2012, pp. 1671-1678. doi:10.1007/s00726-012-1248-4

[222] I. Muqbil, et al., "Old Wine in a New Bottle: The Warburg Effect and Anticancer Mechanisms of Resveratrol," Current Pharmaceutical Design, Vol. 18, No. 12, 2012, pp. 1645-1654. doi:10.2174/138161212799958567

[223] E. Scott, et al., "Resveratrol in Human Cancer Chemoprevention-Choosing the 'Right' Dose," Molecular Nutrition \& Food Research, Vol. 56, No. 1, 2012, pp. 7-13. doi:10.1002/mnfr.201100400

[224]X. Xu, et al., "Resveratrol Attenuates Doxorubicin-Induced Cardiomyocyte Death via Inhibition of P70 S6 Kinase 1-Mediated Autophagy," Journal of Pharmacology and Experimental Therapeutics, Vol. 341, No. 1, 2012, pp. 183-195. doi:10.1124/jpet.111.189589

[225] W. Mo, et al., "Resveratrol Inhibits Proliferation and Induces Apoptosis through the Hedgehog Signaling Pathway in Pancreatic Cancer Cell," Pancreatology, Vol. 11, No. 6, 2011, pp. 601-609. doi:10.1159/000333542

[226] M. U. Nessa, et al., "Combinations of Resveratrol, Cisplatin and Oxaliplatin Applied to Human Ovarian Cancer Cells," Anticancer Research, Vol. 32, No. 1, 2012, pp. 53-59.

[227] J. Ryu, et al., "Resveratrol Reduces TNF-Alpha-Induced U373MG Human Glioma Cell Invasion through Regulating NF-KappaB Activation and uPA/uPAR Expression," Anticancer Research, Vol. 31, No. 12, 2011, pp. 42234230.

[228] T. Erdem, et al., "The Effect of Resveratrol on the Prevention of Cisplatin Ototoxicity," European Archives of Otorhinolaryngology, 2011.

[229] C. C. Lu and J. K. Chen, "Resveratrol Enhances Perforin Expression and NK Cell Cytotoxicity through NKG2DDependent Pathways," Journal of Cellular Physiology, Vol. 223, No. 2, 2010, pp. 343-351.

[230] R. Falchetti, et al., "Effects of Resveratrol on Human Immune Cell Function," Life Sciences, Vol. 70, No. 1, 2001, pp. 81-96.

doi:10.1016/S0024-3205, No. 01)01367-4

[231] Y. Fang, E. J. Herrick and M. B. Nicholl, “A Possible Role for Perforin and Granzyme B in Resveratrol Enhanced Radiosensitivity of Prostate Cancer," Journal of Andrology, 2011.

[232] C. Alvarado, et al., "Improvement of Leukocyte Functions in Young Prematurely Aging Mice after a 5-Week Ingestion of a Diet Supplemented with Biscuits Enriched in Antioxidants," Antioxidants \& Redox Signaling, Vol. 7, No. 9-10, 2005, pp. 1203-1210. doi:10.1089/ars.2005.7.1203

[233] L. D. Koller, et al., "Immune Responses in Rats Supplemented with Selenium," Clinical \& Experimental Immunology, Vol. 63, No. 3, 1986, pp. 570-576.

[234] M. Enqvist, et al., "Selenite Induces Posttranscriptional Blockade of HLA-E Expression and Sensitizes Tumor 
Cells to CD94/NKG2A-Positive NK Cells," The Journal of Immunology, Vol. 187, No. 7, 2011, pp. 3546-3554. doi:10.4049/jimmunol.1100610

[235] W. C. Hawkes, "A. Hwang, and Z. Alkan, The Effect of Selenium Supplementation on DTH Skin Responses in Healthy North American Men," Journal of Trace Elements in Medicine \& Biology, Vol. 23, No. 4, 2009, pp. 272-280. doi:10.1016/j.jtemb.2009.04.002

[236] X. Chen, et al., "Effect of Excessive Iodine on Immune Function of Lymphocytes and Intervention with Selenium," Journal of Huazhong University of Science and Technology-Medical Sciences, Vol. 27, No. 4, 2007, pp. 422-425. doi:10.1007/s11596-007-0418-1

[237] M. F. McCarty and K. I. Block, "Toward a Core Nutraceutical Program for Cancer Management," Integrative Cancer Therapies, Vol. 5, No. 2, 2006, pp. 150-171. doi:10.1177/1534735406288443

[238] C. Klein, et al., "From Food to Nutritional Support to Specific Nutraceuticals: A Journey across Time in the Treatment of Disease," Journal of Gastroenterology, Vol. 35, Suppl. 12, 2000, pp. 1-6.

[239] A. D. Smith, Y. I. Kim and H. Refsum, "Is Folic Acid Good for Everyone?" The American Journal of Clinical Nutrition, Vol. 87, No. 3, 2008, pp. 517-533.

[240] M. A. Erkurt, et al., "Effects of Cyanocobalamin on Immunity in Patients with Pernicious Anemia," Medical Principles and Practice, Vol. 17, No. 2, 2008, pp. 131135. doi:10.1159/000112967

[241] J. Tamura, et al., "Immunomodulation by Vitamin B12: Augmentation of $\mathrm{CD}^{+} \mathrm{T}$ Lymphocytes and Natural Killer (NK) Cell Activity in Vitamin B12-Deficient Patients by Methyl-B12 Treatment," Clinical \& Experimental Immunology, Vol. 116, No. 1, 1999, pp. 28-32. doi:10.1046/j.1365-2249.1999.00870.x

[242] F. Brivio, et al., "Preoperative Interleukin-2 Subcutaneous Immunotherapy May Prolong the Survival Time in Advanced Colorectal Cancer Patients," Oncology, Vol. 53, No. 4, 1996, pp. 263-268. doi:10.1159/000227571

[243] P. H. Nichols, et al., "The Effect of 5-Fluorouracil and Alpha Interferon and 5-Fluorouracil and Leucovorin on Cellular Anti-Tumour Immune Responses in Patients with Advanced Colorectal Cancer," British Journal of Cancer, Vol. 70, No. 5, 1994, pp. 946-949. doi:10.1038/bjc. 1994.426

[244] M. K. Baum, et al., "Association of Vitamin B6 Status with Parameters of Immune Function in Early HIV-1 Infection," Journal of Acquired Immune Deficiency Syndromes, Vol. 4, No. 11, 1991, pp. 1122-1132.

[245] C. Ha, L. T. Miller and N. I. Kerkvliet, "The Effect of Vitamin B6 Deficiency on Cytotoxic Immune Responses of T Cells, Antibodies, and Natural Killer Cells, and Phagocytosis by Macrophages," Cellular Immunology, Vol. 85, No. 2, 1984, pp. 318-329. doi:10.1016/0008-8749, No. 84)90246-6

[246] K. L. Erickson, E. A. Medina and N. E. Hubbard, "Micronutrients and Innate Immunity," The Journal of Infectious Diseases, Vol. 182, Suppl. 1, 2000, pp. S5-S10. doi: $10.1086 / 315922$
[247] B. Atasever, et al., "In Vitro Effects of Vitamin C and Selenium on NK Activity of Patients with Beta-Thalassemia Major," Journal of Pediatric Hematology/Oncology, Vol. 23, No. 3, 2006, pp. 187-197. doi:10.1080/08880010500506420

[248] M. De la Fuente, A. Hernanz and M. C. Vallejo, "The Immune System in the Oxidative Stress Conditions of Aging and Hypertension: Favorable Effects of Antioxidants and Physical Exercise," Antioxidants \& Redox Signaling, Vol. 7, No. 9-10, 2005, pp. 1356-1366. doi:10.1089/ars.2005.7.1356

[249] G. Heuser and A. Vojdani, "Enhancement of Natural Killer Cell Activity and T and B Cell Function by Buffered Vitamin C in Patients Exposed to Toxic Chemicals: The Role of Protein Kinase-C," Immunopharmacol and Immunotoxicol, Vol. 19, No. 3, 1997, pp. 291-312. doi: $10.3109 / 08923979709046977$

[250] D. C. Nieman and B. K. Pedersen, "Exercise and Immune Function. Recent Developments," Sports Medicine, Vol. 27, No. 2, 1999, pp. 73-80. doi:10.2165/00007256-199927020-00001

[251] E. W. Petersen, et al., "Effect of Vitamin Supplementation on Cytokine Response and on Muscle Damage after Strenuous Exercise," American Journal of PhysiologyCell Physiology, Vol. 280, No. 6, 2001, pp. C1570C1575.

[252] D. See, S. Mason and R. Roshan, "Increased Tumor Necrosis Factor Alpha (TNF-Alpha) and Natural Killer Cell (NK) Function Using an Integrative Approach in Late Stage Cancers," Immunological Investigations, Vol. 31, No. 2, 2002, pp. 137-153. doi:10.1081/IMM-120004804

[253] K. Suresh and D. M. Vasudevan, "Augmentation of Murine Natural Killer Cell and Antibody Dependent Cellular Cytotoxicity Activities by Phyllanthus Emblica, a New Immunomodulator," Journal of Ethnopharmacology, Vol. 44, No. 1, 1994, pp. 55-60. doi:10.1016/0378-8741, No. 94)90099-X

[254] I. K. Toliopoulos, et al., "Inhibition of Platelet Aggregation and Immunomodulation of NK Lymphocytes by Administration of Ascorbic Acid," Indian Journal of Experimental Biology, Vol. 49, No. 12, 2011, pp. 904-908.

[255] A. Vojdani, et al., "New Evidence for Antioxidant Properties of Vitamin C," Cancer Detection and Prevention Journal, Vol. 24, No. 6, 2000, pp. 508-523.

[256] E. S. Wintergerst, S. Maggini and D. H. Hornig, "Immune-Enhancing Role of Vitamin $\mathrm{C}$ and Zinc and Effect on Clinical Conditions," Annals of Nutrition and Metabolism, Vol. 50, No. 2, 2006, pp. 85-94. doi:10.1159/000090495

[257] A. E. El-Shazly and P. P. Lefebvre, "Modulation of NK Cell Autocrine-Induced Eosinophil Chemotaxis by Interleukin-15 and Vitamin D3: A Possible NK-Eosinophil Crosstalk via IL-8 in the Pathophysiology of Allergic Rhinitis," Mediators of Inflammation, Vol. 2011, 2011, Article ID: 373589.

[258] K. N. Lee, et al., "VDUP1 Is Required for the Development of Natural Killer Cells," Immunity, Vol. 22, No. 2, 2005, pp. 195-208. doi:10.1016/j.immuni.2004.12.012 
[259] J. H. Ooi, J. Chen and M. T. Cantorna, "Vitamin D Regulation of Immune Function in the Gut: Why Do T Cells Have Vitamin D Receptors?" Molecular Aspects of Medicine, Vol. 33, No. 1, 2012, pp. 77-82. doi:10.1016/j.mam.2011.10.014

[260] A. Rohner, et al., "Differentiation-Promoting Drugs UpRegulate NKG2D Ligand Expression and Enhance the Susceptibility of Acute Myeloid Leukemia Cells to Natural Killer Cell-Mediated Lysis," Leukemia Research, Vol. 31, No. 10, 2007, pp. 1393-1402. doi:10.1016/j.leukres.2007.02.020

[261] X. Wang, N. M. Ponzio and G. P. P. Studzinski, "LongTerm Exposure of HL60 Cells to 1,25-DihydroxyVitamin D3 Reduces Their Tumorigenicity: A Model for Cancer Chemoprevention," Proceedings of the Society for Experimental Biology and Medicine, Vol. 215, No. 4, 1997, pp. 399-404.

[262] S. Yu and M. T. Cantorna, "Epigenetic Reduction in Invariant NKT Cells Following in Utero Vitamin D Deficiency in Mice," The Journal of Immunology, Vol. 186, No. 3, 2011, pp. 1384-1390. doi:10.4049/jimmunol.1002545

[263] S. R. Hafid, A. K. Radhakrishnan and K. Nesaretnam, "Tocotrienols Are Good Adjuvants for Developing Cancer Vaccines," BMC Cancer, Vol. 10, 2010, p. 5. doi:10.1186/1471-2407-10-5

[264] M. G. Hanson, et al., "A Short-Term Dietary Supplementation with High Doses of Vitamin E Increases NK Cell Cytolytic Activity in Advanced Colorectal Cancer Patients," Cancer Immunology, Immunotherapy, Vol. 56, No. 7, 2007, pp. 973-984. doi:10.1007/s00262-006-0261-4

[265] D. Bunout, et al., "Effects of a Nutritional Supplement on the Immune Response and Cytokine Production in FreeLiving Chilean Elderly," Journal of Parenteral and Enteral Nutrition, Vol. 28, No. 5, 2004, pp. 348-354. doi: $10.1177 / 0148607104028005348$

[266] M. A. Beck, D. Williams-Toone and O. A. Levander, "Coxsackievirus B3-Resistant Mice Become Susceptible in Se/Vitamin E Deficiency," Free Radical Biology \& Medicine, Vol. 34, No. 10, 2003, pp. 1263-1270. doi:10.1016/S0891-5849, No. 03)00101-1

[267] C. Y. Lee and J. M. Wan, "Immunoregulatory and Antioxidant Performance of Alpha-Tocopherol and Selenium on Human Lymphocytes," Biological Trace Element Rese, Vol. 86, No. 2, 2002, pp. 123-136. doi:10.1385/BTER:86:2:123

[268] W. J. Evans, "Vitamin E, Vitamin C, and Exercise," The American Journal of Clinical Nutrition, Vol. 72, No. 2, 2000, pp. 647S-652S.

[269] A. S. Prasad, et al., "Zinc in Cancer Prevention," Nutrition and Cancer, Vol. 61, No. 6, 2009, pp. 879-887. doi:10.1080/01635580903285122

[270] M. Stefanidou, et al., "Zinc: A Multipurpose Trace Element," Archives of Toxicology, Vol. 80, No. 1, 2006, pp. 1-9. doi:10.1007/s00204-005-0009-5

[271] C. Alvarado, et al., "Dietary Supplementation with Antioxidants Improves Functions and Decreases Oxidative Stress of Leukocytes from Prematurely Aging Mice,"
Nutrition, Vol. 22, No. 7-8, 2006, pp. 767-777. doi:10.1016/j.nut.2006.05.007

[272] Y. K. Jeon, et al., "Expression of the Promyelocytic Leukemia Zinc-Finger in T-Lymphoblastic Lymphoma and Leukemia Has Strong Implications for Their Cellular Origin and Greater Association with Initial Bone Marrow Involvement," Modern Pathology Advance Online Publication, 2012. doi:10.1038/modpathol.2012.82

[273] P. P. Pereira and L. Boucontet, "Innate NKT $\gamma \delta$ and NKT $\alpha \beta$ Cells Exert Similar Functions and Compete for a Thymic Niche," European Journal of Immunology, Vol. 42, No. 5, 2012, pp. 1272-1281. doi:10.1002/eji.201142109

[274] A. Shimada and S. Hasegawa-Ishii, "Senescence-Accelerated Mice (SAMs) as a Model for Brain Aging and Immunosenescence," Aging and Disease, Vol. 2, No. 5, 2011, pp. 414-435.

[275] J. Yamashita, et al., "Murine Schnurri-2 Controls Natural Killer Cell Function and Lymphoma Development," Leukemia \& Lymphoma, Vol. 53, No. 3, 2012, pp. 479486. doi:10.3109/10428194.2011.625099

[276] S. Y. Thomas, et al., "PLZF Induces an Intravascular Surveillance Program Mediated by Long-Lived LFA-1ICAM-1 Interactions," The Journal of Experimental Medicine, Vol. 208, No. 6, 2011, pp. 1179-1188. doi:10.1084/jem.20102630

[277] E. Mocchegiani, et al., "Zinc, Metallothioneins and Immunosenescence," Proceedings of the Nutrition Society, Vol. 69, No. 3, 2010, pp. 290-299. doi:10.1017/S0029665110001862

[278] Xu, D., et al., Promyelocytic Leukemia Zinc Finger Protein Regulates Interferon-Mediated Innate Immunity," Immunity, Vol. 30, No. 6, 2009, pp. 802-816. doi:10.1016/j.immuni.2009.04.013

[279] E. Mocchegiani, et al., "NK and NKT Cells in Aging and Longevity: Role of Zinc and Metallothioneins," Journal of Clinical Immunology, Vol. 29, No. 4, 2009, pp. 416425. doi:10.1007/s10875-009-9298-4

[280] M. Muzzioli, et al., "Zinc Improves the Development of Human CD $34^{+}$Cell Progenitors towards Natural Killer Cells and Induces the Expression of GATA-3 Transcription Factor," The International Journal of Biochemistry \& Cell Biology, Vol. 39, No. 5, 2007, pp. 955-965. doi:10.1016/j.biocel.2007.01.011

[281] G. Cocchi, et al., "Immunological Patterns in Young Children with Down syndrome: Is There a Temporal Trend?" Acta Paediatrica, Vol. 96, No. 10, 2007, pp. 1479-1482. doi:10.1111/j.1651-2227.2007.00459.x

[282] E. Mariani, et al., "Effect of Zinc Supplementation on Plasma IL-6 and MCP-1 Production and NK Cell Function in Healthy Elderly: Interactive Influence of +647 MT1a and -174 IL-6 Polymorphic Alleles," Experimental Gerontology, Vol. 43, No. 5, 2008, pp. 462-471. doi:10.1016/j.exger.2007.12.003

[283] V. Brazao, et al., "Zinc Supplementation Increases Resistance to Experimental Infection by Trypanosoma Cruzi," Veterinary Parasitology, Vol. 154, No. 1-2, 2008, pp. 3237. doi:10.1016/j.vetpar.2008.02.015

[284] C. H. Metz, et al., “T-Helper Type 1 Cytokine Release Is 
Enhanced by in Vitro Zinc Supplementation Due to Increased Natural Killer Cells," Nutrition, Vol. 23, No. 2, 2007, pp. 157-163. doi:10.1016/j.nut.2006.10.007

[285] O. DelaRosa, et al., "Immunological Biomarkers of Ageing in Man: Changes in both Innate and Adaptive Immunity Are Associated with Health and Longevity," Biogerontology, Vol. 7, No. 5-6, 2006, pp. 471-481. doi:10.1007/s10522-006-9062-6

\section{List of Abbreviations}

1,25(OH) 2D3 1,25-dihydroxyvitamin D3

1,25 D3 1,25-dihydroxyvitamin D3

4NQO 4-nitroquinoline 1-oxide

5-FU 5-fluorouracil

ABGE aged black garlic extracts

AD Alzheimer's disease

ADCC antibody-dependent cell-mediated cytotoxicity

AGE aged garlic extract

ALA alpha-lipoic acid

AmB amphotericin B

AML acute myeloid leukemia

APG acidic polysaccharide of ginseng

ATL adult T-cell leukemia

ATRA chemotherapy for promyelocytic leukemia

AXOS arabinoxylan-oligosaccharides

BAFs breast adipose fibroblasts

BioBran arabinoxylan rice bran

BCC breast cancer cell

BGP boiled garlic powder

BRM biological response modifier

CAM complementary and alternative medicine

cAMP cyclic AMP

CBDCA carboplatin

CD3+ T cell marker

CD4+ helper cell marker

CD8+ suppressor cell marker

CHAX corn husk arabinoxylan

CIPFC complement independent plaque forming cell

CLL chronic lymphocyte leukemia

CPB cardiopulmonary bypass
[286] C. F. Hodkinson, et al., "Zinc Status and Age-Related Changes in Peripheral Blood Leukocyte Subpopulations in Healthy Men and Women Aged 55-70 Y: The ZENITH Study," European Journal of Clinical Nutrition, Vol. 59, Suppl. 2, 2005, pp. S63-S67. doi:10.1038/sj.ejen.1602301

$\begin{array}{ll}\text { CRC } & \text { colorectal cancer } \\ \text { CY } & \text { cyclophosphamide } \\ \text { DADS } & \text { diallyl disulfide } \\ \text { DAS } & \text { diallyl sulfide } \\ \text { DATS } & \text { diallyl trisulfide } \\ \text { DCs } & \text { dendritic cells } \\ \text { DMH } & \text { 1,2-dimethylhydrazine } \\ \text { EC } & \text { effector cells } \\ \text { EMT } & \text { epithelial-mesenchymal transition } \\ \text { Epo } & \text { erythropoietin } \\ \text { ER- } \alpha & \text { estrogen receptor } \\ \text { GEN } & \text { genistein } \\ \text { GSH } & \text { glutathione } \\ \text { GSSG } & \text { glutathione disulfide } \\ \text { H } 2 \text { S } & \text { hydrogen sulfide } \\ \text { HepG2 } & \text { human hepatoma } \\ \text { HL60 } & \text { human promyelocytic leukemia cells } \\ \text { HRB } & \text { hydrolyzed rice bran } \\ \text { IBD } & \text { inflammatory bowel disease } \\ \text { ICAM } & \text { intercellular adhesion molecule } \\ \text { IFN-alpha } \quad \text { interferon-alpha } \\ \text { IFN-gamma interferon-gamma } \\ \text { IFNs } & \text { interferons } \\ \text { IL } & \text { interleukin } \\ \text { IL-1 } & \text { interleukin-1 } \\ \text { IL-2 } & \text { interleukin-2 } \\ \text { IL-4 } & \text { interleukin-4 } \\ \text { IL-6 } & \text { interleukin-6 } \\ \text { IL-8 } & \text { interleukin- } 8 \\ \text { IL-12 } & \text { interleukin-12 } \\ \text { IL-13 } & \text { interleukin-13 } \\ \text { IL2R } & \text { interleukin-2 receptor } \\ & \end{array}$




$\begin{array}{ll}\text { iNKCT } & \text { invariant NKCT } \\ \text { LA } & \text { lipoicacid } \\ \text { LAC } & \text { lactacystin } \\ \text { LAK } & \text { lymphokine activated killer } \\ \text { LDCC } & \text { lectin-dependent cell-mediated cytotoxicity } \\ \text { LEN } & \text { lentinan } \\ \text { LGL } & \text { granular lymphocytes } \\ \text { LPS } & \text { lipopolysaccharides } \\ \text { MAPK } & \text { mitogen activated protein kinase } \\ \text { MCF-7 } & \text { sensitive human breast carcinoma cells } \\ \text { MDR } & \text { multidrug resistance } \\ \text { MEFs } & \text { murine embryonic fibroblasts } \\ \text { MGN-3Arabinoxylan rice bran } \\ \text { MLs } & \text { mistletoe lectins } \\ \text { MM } & \text { multiple myeloma } \\ \text { MMP-2 } & \text { matrix metalloproteinase-2 } \\ \text { MMPs } & \text { matrix metalloproteinases } \\ \text { MPS } & \text { myofascial pain syndrome } \\ \text { MRP2 } & \text { multidrug resistance protein } 2 \\ \text { MS } & \text { multiple sclerosis } \\ \text { MTs } & \text { metallothioneins } \\ \text { MW } & \text { molecular weight } \\ \text { NASH } & \text { non-alcoholic steatohepatitis } \\ \text { NFAT } & \text { nuclear factor of activated T-cells } \\ \text { NKC } & \text { natural killer cell } \\ \text { OSCC } & \text { oral squamous cell carcinoma } \\ \text { OSCs } & \text { organosulfur compounds } \\ \text { PAM } & \text { prematurely aging mice } \\ \text { PBL } & \text { peripheral blood lymphocytes } \\ \text { PBMC } & \text { peripheral blood mononuclear cells } \\ \text { PC } & \text { prostate cancer } \\ & \end{array}$

PgR progesterone receptor

PKA protein kinase A

PFC plaque forming cell

PLZF promyelocytic leukemia zinc-finger

PNAC peripheral non-adherent cells

PTK protein tyrosine kinase

PVR poliovirus receptor

RES resveratrol

rIL-2 recombinant interleukin-2

ROS reactive oxygen species

RFC rosette forming cells (T-cells)

SAC S-allyl cysteine

SAM senescence-accelerated mouse

SAMC S-allylmercaptocysteine

SEM scanning electron microscopy

SCD1 stearoyl-CoA desaturase-1

SCT stem cell transplantation

Se selenium

SFN sulforaphane

SMI shenmai injection

SRBC sheep red blood cells

TNF- $\alpha$ tumor necrosis factor-alpha

TP thioproline

TEM transmission electron microscopy

TRF tocotrienol-rich fraction

Vcr-R resistant human breast carcinoma cells

VDUP1 vitamin D3 up regulated protein 1

VEGF vascular endothelial growth factor

XIAP X-linked inhibitor of apoptosis

$\mathrm{Zn} \quad$ zinc 